\title{
Oriented Assembly of 2D Metal-Pyridylporphyrinic Framework Films for Giant Nonlinear Optical Limiting
}

De-Jing Liac\#, Qiao-hong Li ia\#, Zhi-Gang Guab* and Jian Zhangabc

${ }^{a}$ State Key Laboratory of Structural Chemistry, Fujian Institute of Research on the

Structure of Matter, Chinese Academy of Sciences, Fuzhou, Fujian 350002, China.

${ }^{b}$ Fujian Science \& Technology Innovation Laboratory for Optoelectronic Information of China, Fuzhou, Fujian 350108, China.

' University of Chinese Academy of Sciences, Beijing 100049, China.

${ }^{\#}$ The authors contributed equally to this work.

Address correspondence to zggu@,fjirsm.ac.cn 
Table of content

Scheme S1. Synthetic route for TPyP(M) $(\mathrm{M}=\mathrm{Cu}, \mathrm{Ni}, \mathrm{Mn})$.

Figure S1. The structure of $\mathrm{ZnTPyP}(\mathrm{M})\left(\mathrm{M}=\mathrm{Cu}, \mathrm{Ni}, \mathrm{Mn}, \mathrm{H}_{2}\right)$.

Figure S2. The IR spectrum for $\operatorname{TPyP}(M)\left(M=C u, N i, M n, H_{2}\right)$.

Figure S3. The UV-vis absorption spectrum for TPyP(M) $\left(\mathrm{M}=\mathrm{Cu}, \mathrm{Ni}, \mathrm{Mn}, \mathrm{H}_{2}\right)$.

Figure S4. The IR spectrum of $\mathrm{ZnTPyP}(\mathrm{M})\left(\mathrm{M}=\mathrm{Cu}, \mathrm{Ni}, \mathrm{Mn}, \mathrm{H}_{2}\right)$ films.

Figure S5. UV-vis absorption spectrum of the $\mathrm{ZnTPyP}(\mathrm{M})\left(\mathrm{M}=\mathrm{Cu}, \mathrm{Ni}, \mathrm{Mn}, \mathrm{H}_{2}\right)$ films.

Figure S6. The SEM images of $\mathrm{ZnTPyP}(\mathrm{M})\left(\mathrm{M}=\mathrm{Ni}, \mathrm{Mn}, \mathrm{H}_{2}\right)$ films.

Figure S7. The AFM images of ZnTPyP(M) $\left(\mathrm{M}=\mathrm{Ni}, \mathrm{Mn}, \mathrm{H}_{2}\right)$ films.

Figure S8. The TEM images of $\mathrm{ZnTPyP}(\mathrm{M})\left(\mathrm{M}=\mathrm{Ni}, \mathrm{Mn}, \mathrm{H}_{2}\right)$ films.

Figure S9. The survey XPS spectra of $\mathrm{ZnTPyP}(\mathrm{Cu})$ film.

Figure S10. Zn 2p XPS spectra of ZnTPyP(Cu) film.

Figure S11. Cu 2p XPS spectra of $\mathrm{ZnTPyP}(\mathrm{Cu})$ film.

Figure S12. N 1s XPS spectra ZnTPyP(Cu) film.

Figure S13. The XPS spectra of $\mathrm{ZnTPyP}\left(\mathrm{H}_{2}\right)$ film.

Figure S14. The XPS spectra of ZnTPyP(Ni) film.

Figure S15. The XPS spectra of ZnTPyP(Mn) film.

Figure S16. The open-aperture Z-scan plots of bare glass. 
Figure S17. The curves of output fluence versus input fluence for ZnTPyP(M) $(\mathrm{M}=$ $\mathrm{Cu}, \mathrm{Ni}, \mathrm{Mn}, \mathrm{H}_{2}$ ) films.

Figure S18. The photocurrent properties for $\mathrm{ZnTPyP}(\mathrm{M})\left(\mathrm{M}=\mathrm{Cu}, \mathrm{Ni}, \mathrm{Mn}, \mathrm{H}_{2}\right)$ films.

Figure S19. The open-aperture Z-scan curves of TPyP(M) $\left(\mathrm{M}=\mathrm{Cu}, \mathrm{Ni}, \mathrm{Mn}, \mathrm{H}_{2}\right)$ ligand solution.

Figure S20. The electronic density of states (DOS) of the $\mathrm{ZnTPyP}(\mathrm{M})(\mathrm{M}=\mathrm{Cu}, \mathrm{Ni}$, $\mathrm{Mn}, \mathrm{H}_{2}$ ) models.

Figure S21. The calculated UV-vis absorption spectra for $\mathrm{ZnTPyP}(M)(\mathrm{M}=\mathrm{Cu}, \mathrm{Ni}$, $\mathrm{Mn}, \mathrm{H}_{2}$ ) models.

Figure S22. The distribution range and the distribution breadth overlap of the excited holes and electrons in ZnTPyP(Ni) (a, b) and ZnTPyP(Mn) model (c, d).

Table S1. Linear and NLO data of the ZnTPyP(M) $\left(\mathrm{M}=\mathrm{Cu}, \mathrm{Ni}, \mathrm{Mn}, \mathrm{H}_{2}\right)$ films.

Table S2. NLO data for this work and some literature examples.

Table S3. The second hyperpolarizabilities $(\gamma)$ of $\mathrm{ZnTPyP}(\mathrm{M})\left(\mathrm{M}=\mathrm{Cu}, \mathrm{Ni}, \mathrm{Mn}, \mathrm{H}_{2}\right)$ models calculated by the CPHF method.

Table S4. Crucial vertical excitation properties of $\mathrm{ZnTPyP}(\mathrm{M})\left(\mathrm{M}=\mathrm{Cu}, \mathrm{Ni}, \mathrm{Mn}, \mathrm{H}_{2}\right)$ models.

Table S5. The strongest excited characteristics of $\mathrm{ZnTPyP}(\mathrm{M})\left(\mathrm{M}=\mathrm{Cu}, \mathrm{Ni}, \mathrm{Mn}, \mathrm{H}_{2}\right)$ models.

Table S6. The corresponding parameters of holes and electrons for ZnTPyP(M) (M $=\mathrm{Cu}, \mathrm{Ni}, \mathrm{Mn}, \mathrm{H}_{2}$ ) models. 


\section{Experimental Section}

Materials and instrumentation: All of the chemicals were used after purchasing without further purification. The Powder X-ray diffraction (PXRD) analysis were performed on a MiniFlex2 X-ray diffractometer using $\mathrm{Cu}-\mathrm{K} \alpha$ radiation $(\lambda=0.1542 \mathrm{~nm})$ in the $2 \theta$ range of $5-20^{\circ}$ with a scanning rate of $0.5^{\circ} \mathrm{min}^{-1}$. IRRAS data were recorded using a Bruker Vertex 70 FTIR spectrometer with $2 \mathrm{~cm}^{-1}$ resolution at an angle of incidence of $80^{\circ}$ relative to the surface normal. Scanning electron microscope (SEM) images for the morphology of ZnTPyP(M) films were measured by JSM6700. JEM2010F was used to record transmission electron microscope (TEM) images and EDS for the samples. The AFM images were recorded with a Bruker Dimension ICON. Xray photoelectron spectroscopy (XPS) spectra for the samples were recorded by using an ESCALAB250Xi. The UV-vis spectra for the samples were measured by Lambda 365. Photocurrent measurement was carried out by using a CHI760e electrochemical workstation (Shanghai Chenhua Instrument China).

Procedures for ligand synthesis: Ligands of the metallated analogues (ТРуР(M), $\mathrm{M}=$ $\mathrm{Cu}, \mathrm{Ni}, \mathrm{Mn})$ of 5,10,15,20-tetrakis(4-pyridyl)porphyrin $\left(\mathrm{TPyP}\left(\mathrm{H}_{2}\right)\right)$ were synthesized based on $\operatorname{TPyP}\left(\mathrm{H}_{2}\right) \cdot{ }^{1-2}$

(1) 5,10,15,20-tetrakis(4-pyridyl)porphyrin(Cu) (TPyP(Cu)): A solution of $\mathrm{TPyP}\left(\mathrm{H}_{2}\right)$ $(0.62 \mathrm{~g}, 1.0 \mathrm{mmol})$ and $\mathrm{Cu}\left(\mathrm{NO}_{3}\right)_{2} \cdot 3 \mathrm{H}_{2} \mathrm{O}(2.41 \mathrm{~g}, 10 \mathrm{mmol})$ in $100 \mathrm{~mL}$ of $\mathrm{CHCl}_{3}$ (mixed by $30 \mathrm{~mL}$ of $\mathrm{CH}_{3} \mathrm{OH}$ ) and the mixture was heated to reflux for $12 \mathrm{~h}$. After cooling down to room temperature, the $\mathrm{CHCl}_{3} / \mathrm{CH}_{3} \mathrm{OH}$ was removed under reduced pressure. The obtained solid was washed three times with water and methanol, and then dried. 
(2) 5,10,15,20-tetrakis(4-pyridyl)porphyrin(Ni) (TPyP(Ni)): The mixture of solution of TPyP $\left(\mathrm{H}_{2}\right)(0.62 \mathrm{~g}, 1.0 \mathrm{mmol})$ and $\mathrm{Ni}\left(\mathrm{NO}_{3}\right)_{2} \cdot 6 \mathrm{H}_{2} \mathrm{O}(2.91 \mathrm{~g}, 10 \mathrm{mmol})$ in $100 \mathrm{~mL}$ of $\mathrm{CHCl}_{3}$ (mixed by $30 \mathrm{~mL}$ of $\mathrm{CH}_{3} \mathrm{OH}$ ) was heated to reflux for $12 \mathrm{~h}$. After cooling down to room temperature, the $\mathrm{CHCl}_{3} / \mathrm{CH}_{3} \mathrm{OH}$ was removed under reduced pressure. The obtained solid was washed three times with water and methanol, dried to give quantitative dark red powder.

(3) 5,10,15,20-tetrakis(4-pyridyl)porphyrin(Mn) (TPyP(Mn)): The mixture of solution of $\operatorname{TPyP}\left(\mathrm{H}_{2}\right)(0.62 \mathrm{~g}, 1.0 \mathrm{mmol})$ and $\mathrm{Mn}\left(\mathrm{NO}_{3}\right)_{2} \cdot 4 \mathrm{H}_{2} \mathrm{O}(2.51 \mathrm{~g}, 10 \mathrm{mmol})$ in $100 \mathrm{~mL}$ of $\mathrm{CHCl}_{3}$ (mixed by $30 \mathrm{~mL}$ of $\mathrm{CH}_{3} \mathrm{OH}$ ) was heated to reflux for $12 \mathrm{~h}$. After cooling down to room temperature, the $\mathrm{CHCl}_{3} / \mathrm{CH}_{3} \mathrm{OH}$ was removed under reduced pressure. The obtained solid was washed three times with water and methanol, dried to give quantitative dark red powder.

Preparation of functionalized quartz glass substrates: The functionalized quartz substrates were treated with a mixture of concentrated $\mathrm{KOH}(2 \mathrm{mmol})$ aqueous solution and hydrogen peroxide $(30 \%)$ with a volume ratio $3: 1$ at $80{ }^{\circ} \mathrm{C}$ for 30 minutes and then cleaned with deionized water and dried under nitrogen flux for the next preparation.

Fabrication of ZnTPyP(M) films: The ZnTPyP(M) films were fabricated using the following ethanolic solutions: zinc (II) acetate (1.0 mM) and ТРуР(M) (0.05 mM). Fristly, the functionalizd quartz glass was immersed in the solution of $\mathrm{Zn}(\mathrm{OAc})_{2}$ for 10 min and then was immersed in $\mathrm{TPyP}(\mathrm{M})$ solution for $15 \mathrm{~min}$. Each step was washed with ethanol to remove residual reactants. A total of 10 growth cycles were used for in 
situ LPE layer-by-layer ZnTPyP(M) films in this work.

Z-scan measurements: The nonlinear optical properties of the $\mathrm{ZnTPyP}(\mathrm{M})$ films were evaluated using the Z-scan technique. The excitation light source was an Nd:YAG laser with a repetition rate of $5 \mathrm{~Hz}$. The laser pulses (period, $5 \mathrm{~ns}$; wavelength, $532 \mathrm{~nm}$ ) were split into two beams with a mirror. The pulse energies at the front and back of the samples were monitored using energy detectors 1 and 2. All of the measurements were conducted at room temperature. The sample was mounted on a computer-controlled translation stage that shifted each sample along the Z-axis.

Calculation of the nonlinear optical parameters: The imaginary parts of the thirdorder susceptibility $\left(\operatorname{Im} \chi^{(3)}\right)$ and the real parts of third-order susceptibility $\left(\operatorname{Re} \chi^{(3)}\right)$ were determined through relations ${ }^{3}$ :

$$
\begin{aligned}
& \operatorname{Im} \chi^{(3)}(e s u)=\frac{c^{2} n_{0}^{2} \beta(m / W)}{240 \pi^{2} \omega} \\
& \operatorname{Re} \chi^{(3)}(e s u)=\frac{c n_{0}^{2} n_{2}\left(m^{2} / W\right)}{120 \pi^{2}}
\end{aligned}
$$

Where $\omega$ is angular frequency of the incident wavelength, $\beta$ is the nonlinear absorption coefficient, $\mathrm{n}_{2}$ is the nonlinear refractive index parameter, $c$ is the speed of light in vacuum, $\lambda$ is the wavelength of the laser pulse and $n_{0}$ is the linear refractive index , respectively.

The absolute value of the third-order NLO susceptibility $\left(\chi^{(3)}\right)$ of the ZnTPyP(M) films were determined according to the following relations: 


$$
\left|\chi^{(3)}\right|=\sqrt{\left|\left(\operatorname{Re} \chi^{(3)}\right)\right|^{2}+\left|\left(\operatorname{Im} \chi^{(3)}\right)\right|^{2}}
$$

The relationship of the sample transmission and input laser intensity for a spatially Gaussian beam could be plotted from the open-aperture Z-scan curve. From the input laser pulse energy $E_{\text {in }}$ and beam radius $\omega(z)$, the light fluence $F_{\text {in }}(z)$ at any position could be obtained. $F_{\text {in }}(z)$ was defined as ${ }^{4}$ :

$$
F_{\text {in }}(z)=\frac{4 E_{\text {in }} \sqrt{\ln 2}}{\pi^{\frac{3}{2}} \omega(z)^{2}}
$$

Where $\omega(z)$ was defined as:

$$
\omega(z)=\omega_{0}\left[1+\left(\frac{z}{z_{0}}\right)^{2}\right]^{\frac{1}{2}}
$$

where $\omega_{0}$ and $\mathrm{z}_{0}$ are the light beam radius and the Rayleigh range, respectively, and $\mathrm{z}_{0}$ was defined as:

$$
z_{0}=\frac{k \omega_{0}^{2}}{2}
$$

Where $k$ was defined as:

$$
k=\frac{2 \pi}{\lambda}
$$

The curve of output fluence versus input fluence in Figure S17 was plotted from Figure 2(a).

The equation fits for the nonlinear adsorption coefficient $\beta$ as follows: 


$$
\begin{gathered}
T(Z, S=1)=\frac{1}{\sqrt{\pi}(Z, 0)} \int_{-\infty}^{\infty} \operatorname{Ln}\left[1+q_{0}(Z, 0) e^{-r^{2}}\right] d r \\
q_{0}(Z, 0)=\beta I_{0} L_{e f f} \\
L_{e f f}=\frac{1-e^{-\alpha l}}{\alpha}
\end{gathered}
$$

In these equations, $I_{0}$ is the on-axis peak intensity at the focus $(\mathrm{Z}=0), L_{\text {eff }}$ is the effective thickness of the sample, $\alpha$ is the linear absorption coefficient, and $l$ is the sample thickness.

DFT Calculations: All the calculations were using Gaussian $16^{5}$. The ground-state equilibrium geometries of ZnTPyP(M) were fully optimized using PBE0 functional, which have been applied to similar systems. ${ }^{6}$ Multiwfn software ${ }^{7}$ was used to analyse the electronic structures, excitation characteristics and hyperpolarizability. The NLO was calculated by the sum-over-states (SOS) method. ${ }^{8}$ The frequency-dependent hyperpolarizabilities could be calculated from the energy of each excited state and the transition dipole moment between each excited state. As shown in the following formula:

$$
\begin{gathered}
\beta_{A B C}\left(-\omega_{\sigma} ; \omega_{1}, \omega_{2}\right)=\hat{P}\left[\mathrm{~A}\left(-\omega_{\sigma}\right), \mathrm{B}\left(\omega_{1}\right), \mathrm{C}\left(\omega_{2}\right)\right] \sum_{i \neq 0} \sum_{j \neq 0} \frac{\mu_{0 i}^{A} \overline{\mu_{i j}^{B}} \mu_{j 0}^{C}}{\left(\Delta_{i}-\omega_{\sigma}\right)\left(\Delta_{j}-\omega_{2}\right)} \\
\gamma_{A B C D}\left(-\omega_{\sigma} ; \omega_{1}, \omega_{2}, \omega_{3}\right)=\hat{P}\left[\mathrm{~A}\left(-\omega_{\sigma}\right), \mathrm{B}\left(\omega_{1}\right), \mathrm{C}\left(\omega_{2}\right), \mathrm{D}\left(\omega_{3}\right)\right]\left(\gamma^{1}-\gamma^{2}\right) \\
\gamma^{1}=\sum_{i=0} \sum_{j=0} \sum_{k=0} \frac{\mu_{0 i}^{A} \overline{\mu_{i j}^{B}} \mu_{j k}^{C} \mu_{k 0}^{D}}{\left(\Delta_{i}-\omega_{\sigma}\right)\left(\Delta_{j}-\omega_{2}-\omega_{3}\right)\left(\Delta_{k}-\omega_{3}\right)}
\end{gathered}
$$




$$
\gamma^{I I}=\sum_{i \neq 0 j=0} \sum_{j=0}^{\mu_{0 i}^{A} \mu_{i}^{B} \mu_{0}^{C} \mu_{j 0}^{D}} \frac{\left.\Delta_{i}-\omega_{\sigma}\right)\left(\Delta_{j}-\omega_{1}\right)\left(\Delta_{j}-\omega_{3}\right)}{\left(\Delta_{i}\right.}
$$

A,B,C... denote one of directions; $\omega$ is energy of external fields; $\Delta_{i}$ stands for excitation energy of state $i$ with respect to ground state $0 ; \mu_{i j}^{A}$ is a component of transition dipole moment between state $i$ and $j$.

The magnitude of hyperpolarizability was used to quantitatively study the nonlinear polarizability of the system.

$$
\begin{aligned}
& \beta_{t o t}=\sqrt{\beta_{x}^{2}+\beta_{y}^{2}+\beta_{z}^{2}} \\
& \gamma_{t o t}=\sqrt{\gamma_{x}^{2}+\gamma_{y}^{2}+\gamma_{z}^{2}}
\end{aligned}
$$

The second and third nonlinear optical polarizability density along the backbone was calculated. The hyperpolarizability of oligomer unit was obtained by contrasting between the dipole moment after Taylor expansion and electron density:

$$
\begin{gathered}
\mu(\mathrm{F})=-\frac{\partial E}{\partial F}=\mu_{0}+\alpha F+\left(\frac{1}{2}\right) \beta F^{2}+\left(\frac{1}{6}\right) \gamma F^{3}+\ldots \\
\rho_{x x x}^{(3)}=\rho^{(0)}(r)+\rho^{(1)}(r) F+\left(\frac{1}{2}\right) \rho^{(2)}(r) F+\left(\frac{1}{6}\right) \rho^{(3)}(r) F^{3}+\ldots \\
\gamma_{x x x x}=\int-\rho_{x x x}^{(3)}(r) x d r \\
\rho_{x x x}^{(3)}=\frac{\rho\left(2 F^{x}\right)-2 \rho\left(2 F^{x}\right)+2 \rho\left(-F^{x}\right)-\rho\left(-2 F^{x}\right)}{2\left(F^{x}\right)^{3}}
\end{gathered}
$$




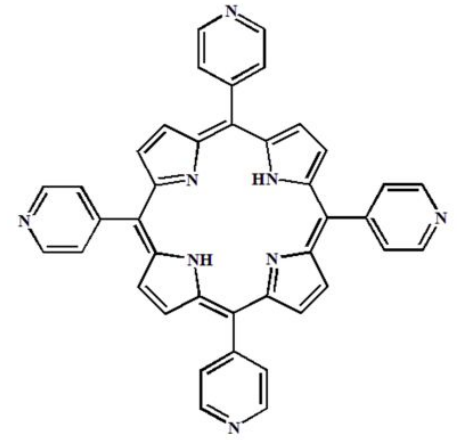

$\operatorname{TPyP}\left(\mathrm{H}_{2}\right)$

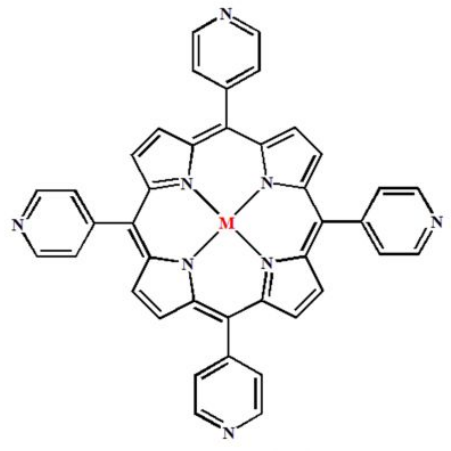

TPyP(M)

Scheme S1. Synthetic route for TPyP(M) $(\mathrm{M}=\mathrm{Cu}, \mathrm{Ni}, \mathrm{Mn})$.

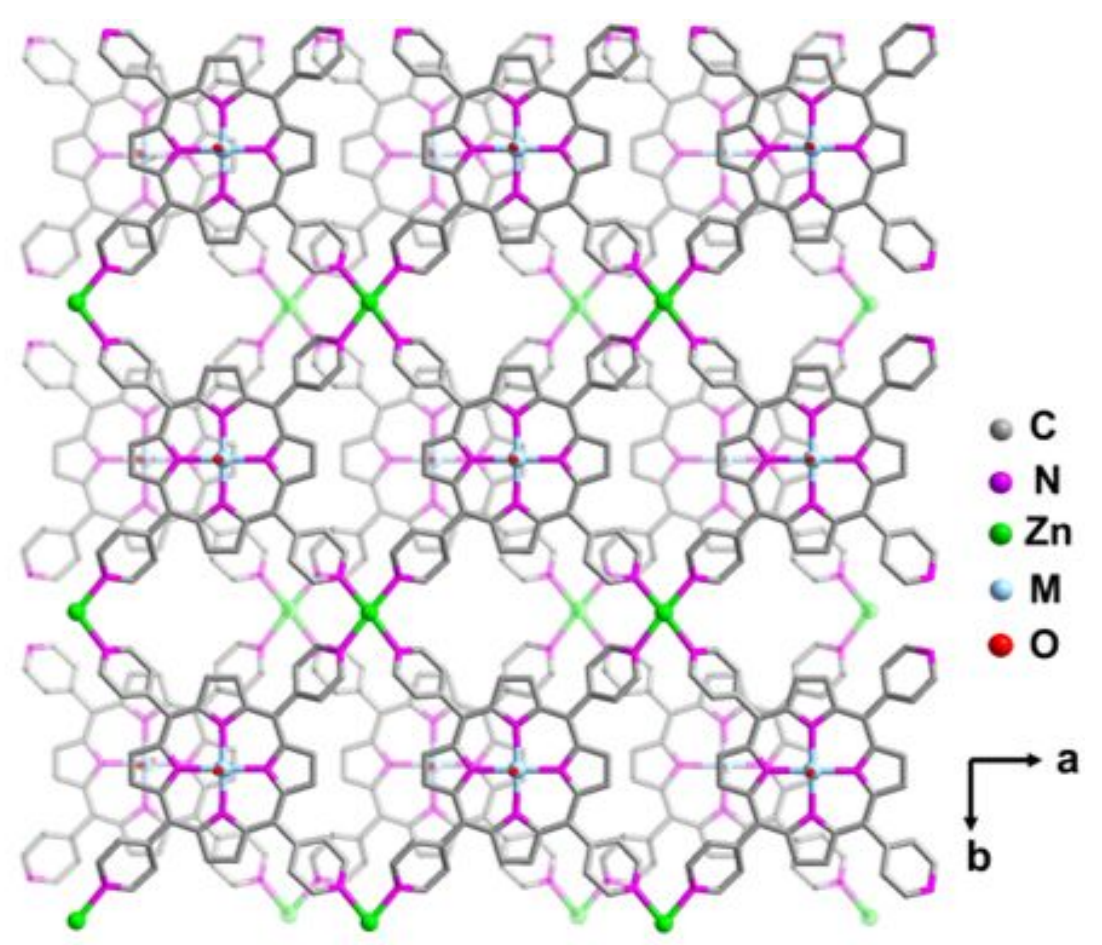

Figure S1. The structure of $\mathrm{ZnTPyP}(\mathrm{M})\left(\mathrm{M}=\mathrm{Cu}, \mathrm{Ni}, \mathrm{Mn}, \mathrm{H}_{2}\right)$. 


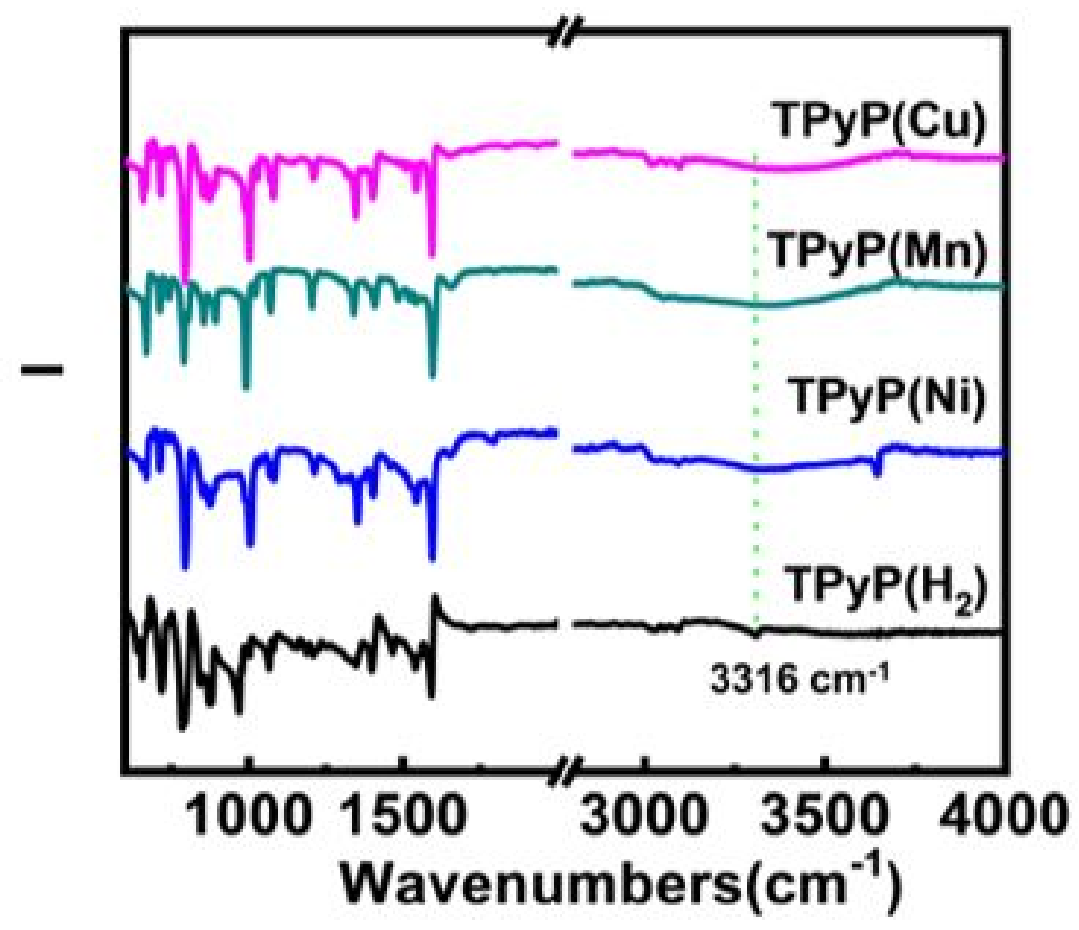

Figure S2. The IR spectrum for $\operatorname{TPyP}(M)\left(M=\mathrm{Cu}, \mathrm{Ni}, \mathrm{Mn}, \mathrm{H}_{2}\right)$.

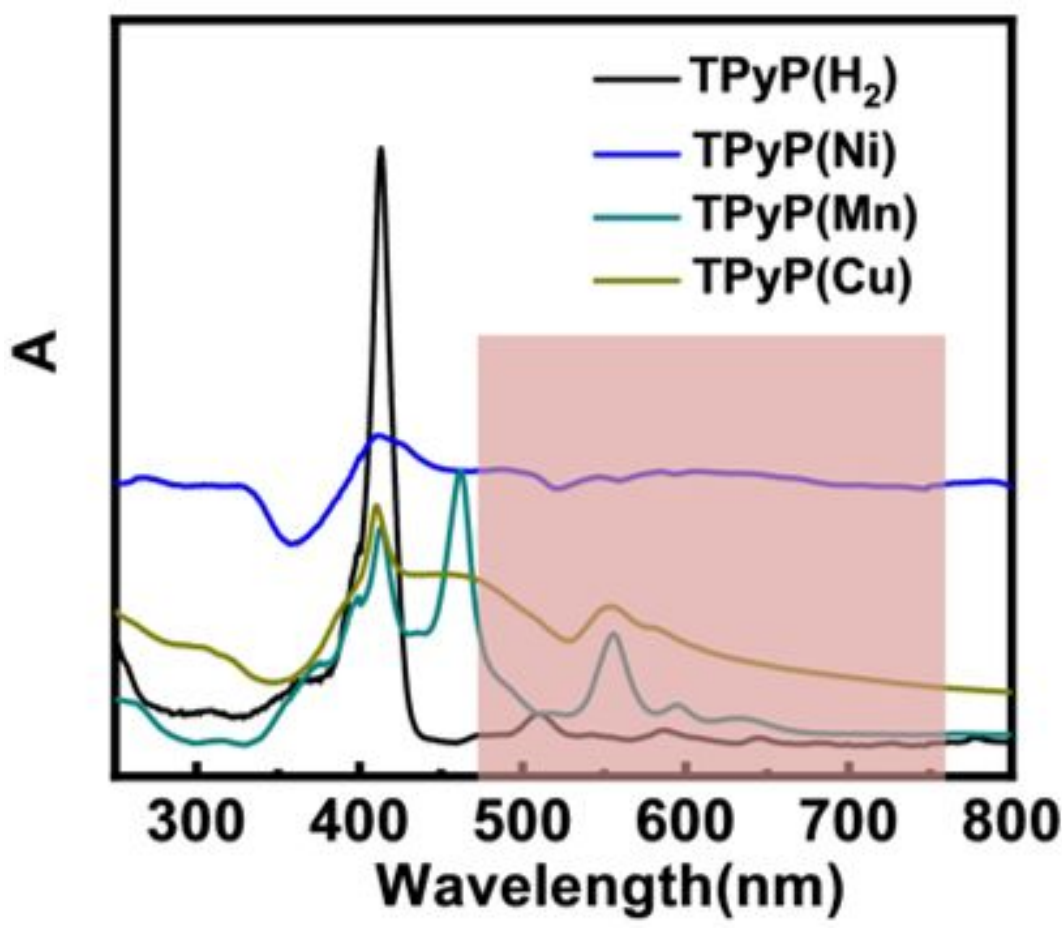

Figure S3. The UV-vis absorption spectrum for TPyP(M) $\left(\mathrm{M}=\mathrm{Cu}, \mathrm{Ni}, \mathrm{Mn}, \mathrm{H}_{2}\right)$. 


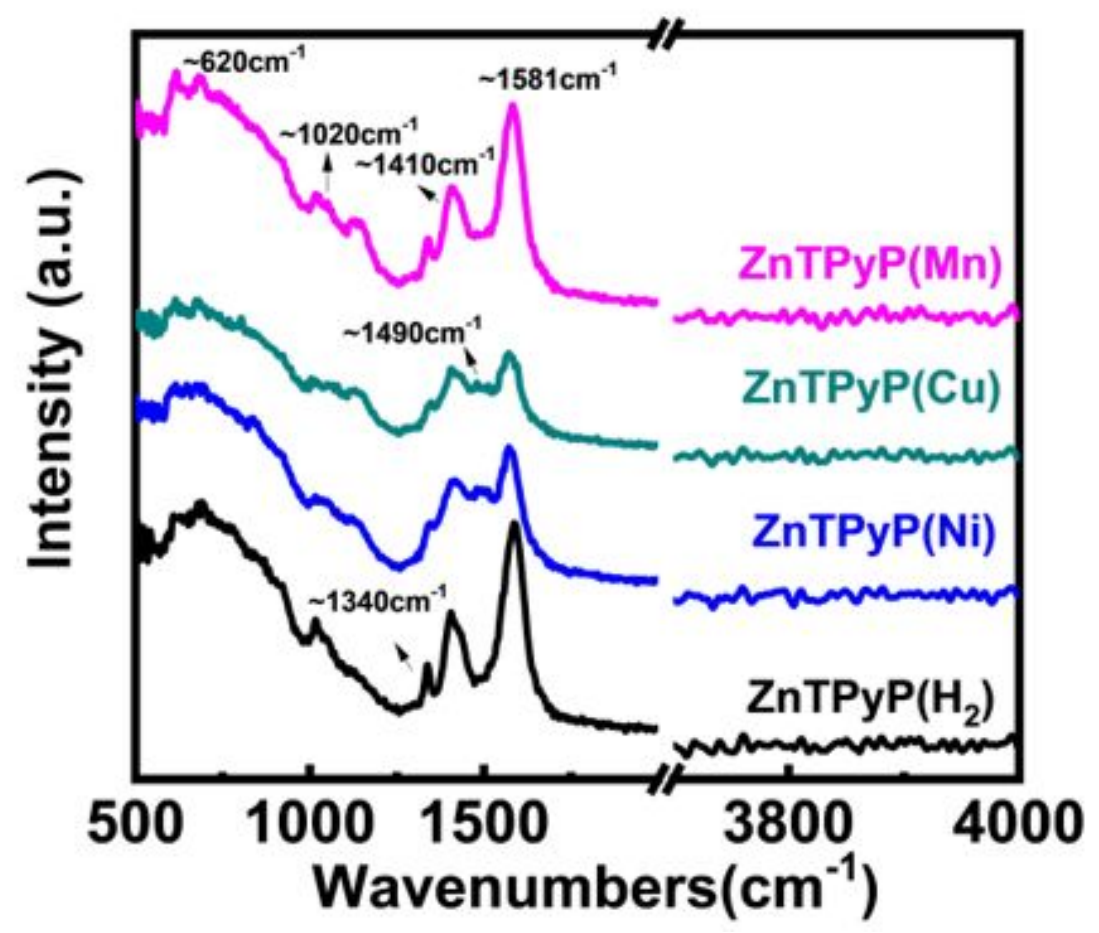

Figure S4. The IR spectrum of $\mathrm{ZnTPyP}(\mathrm{M})\left(\mathrm{M}=\mathrm{Cu}, \mathrm{Ni}, \mathrm{Mn}, \mathrm{H}_{2}\right)$ films.

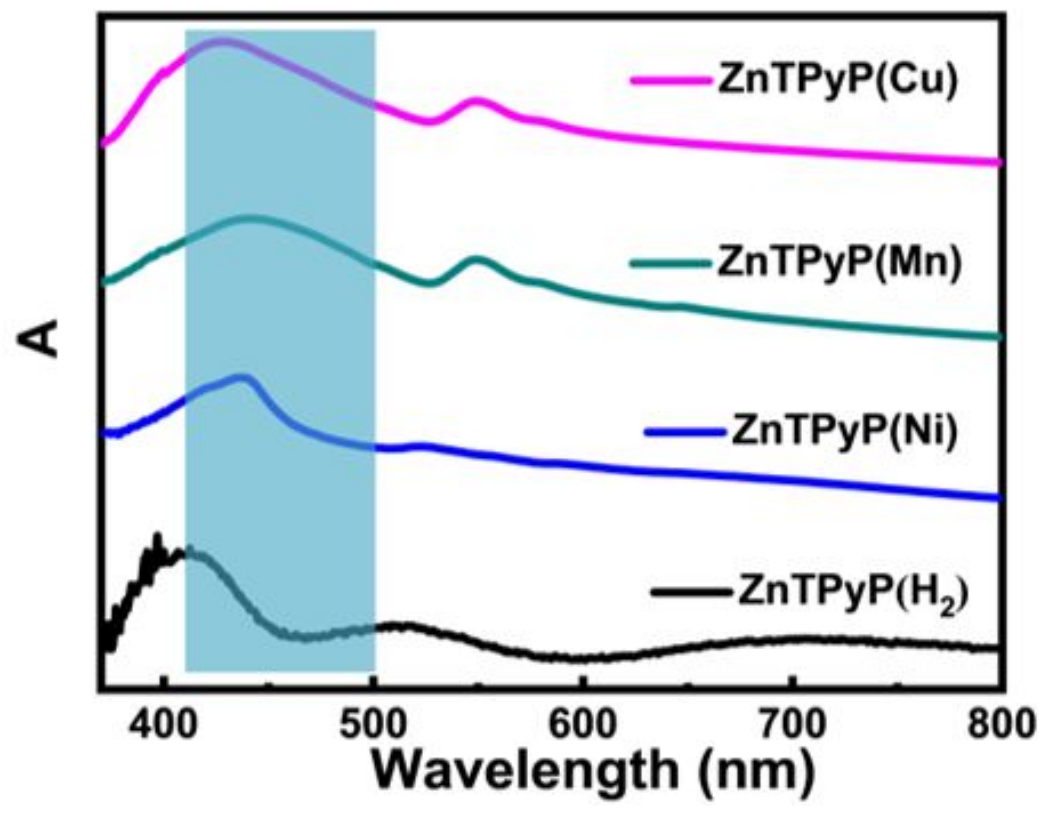

Figure S5. UV-vis absorption spectrum of the $\mathrm{ZnTPyP}(\mathrm{M})\left(\mathrm{M}=\mathrm{Cu}, \mathrm{Ni}, \mathrm{Mn}, \mathrm{H}_{2}\right)$ films. 

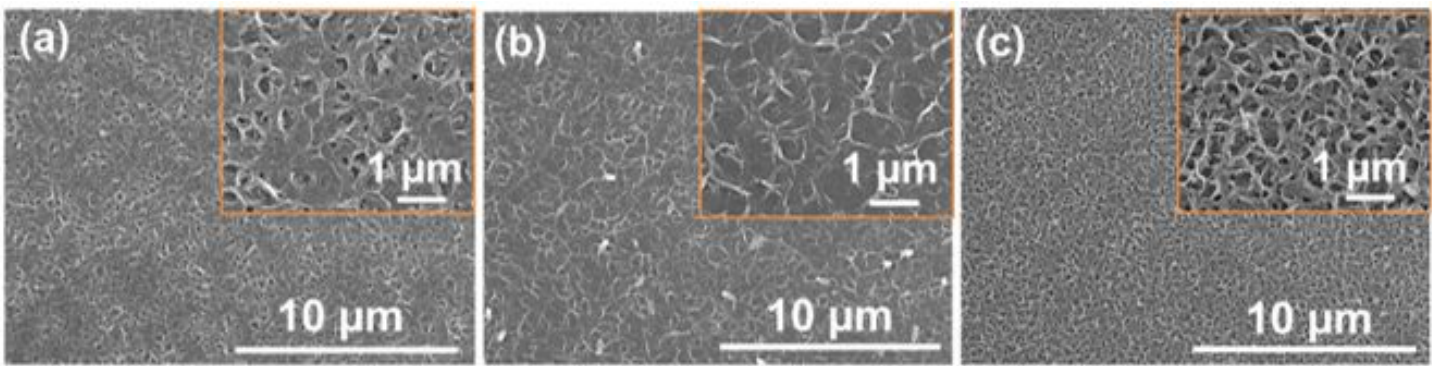

Figure S6. The SEM images of ZnTPyP(M) (M = Ni, Mn, $\left.\mathrm{H}_{2}\right)$ films.
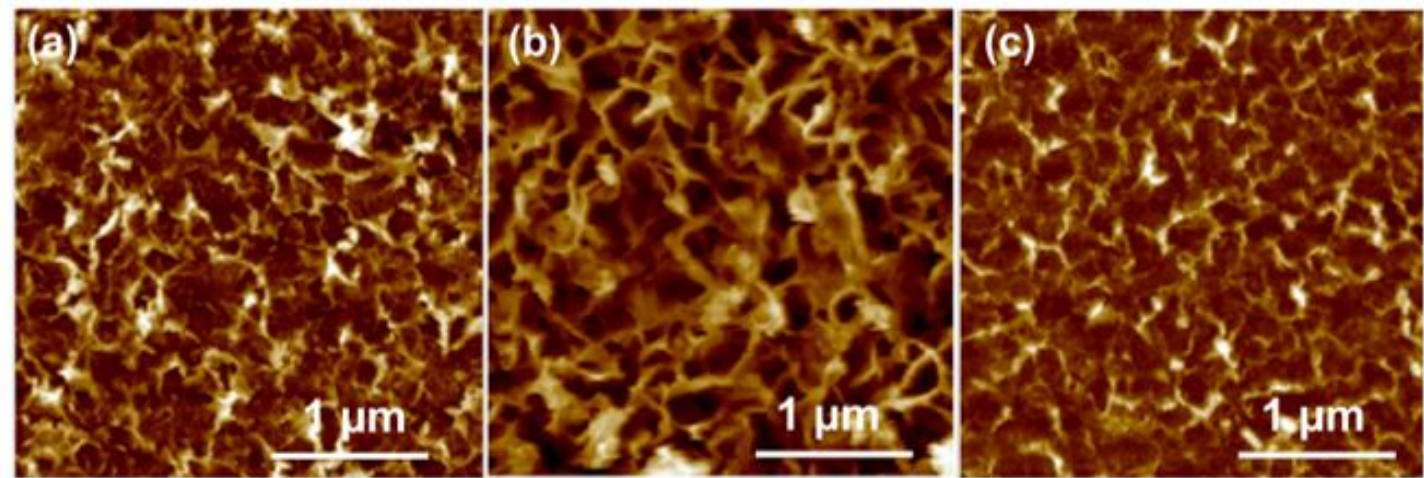

Figure S7. The AFM images of $\mathrm{ZnTPyP}(\mathrm{M})\left(\mathrm{M}=\mathrm{Ni}, \mathrm{Mn}, \mathrm{H}_{2}\right)$ films.
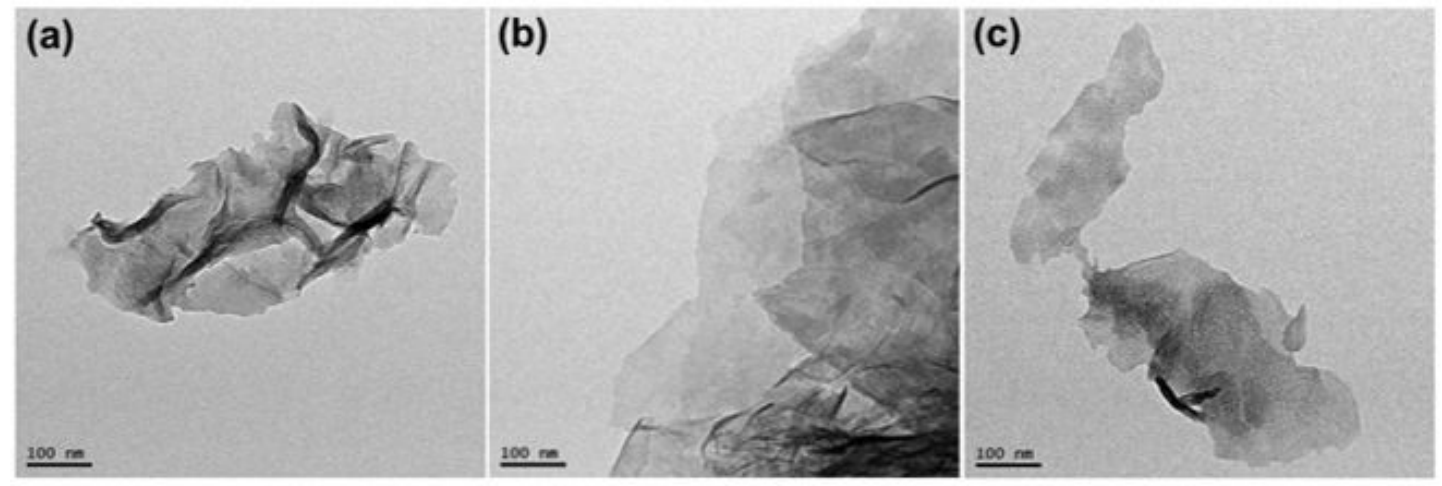

Figure S8. The TEM images of $\mathrm{ZnTPyP}(\mathrm{M})\left(\mathrm{M}=\mathrm{Ni}, \mathrm{Mn}, \mathrm{H}_{2}\right)$ films. 


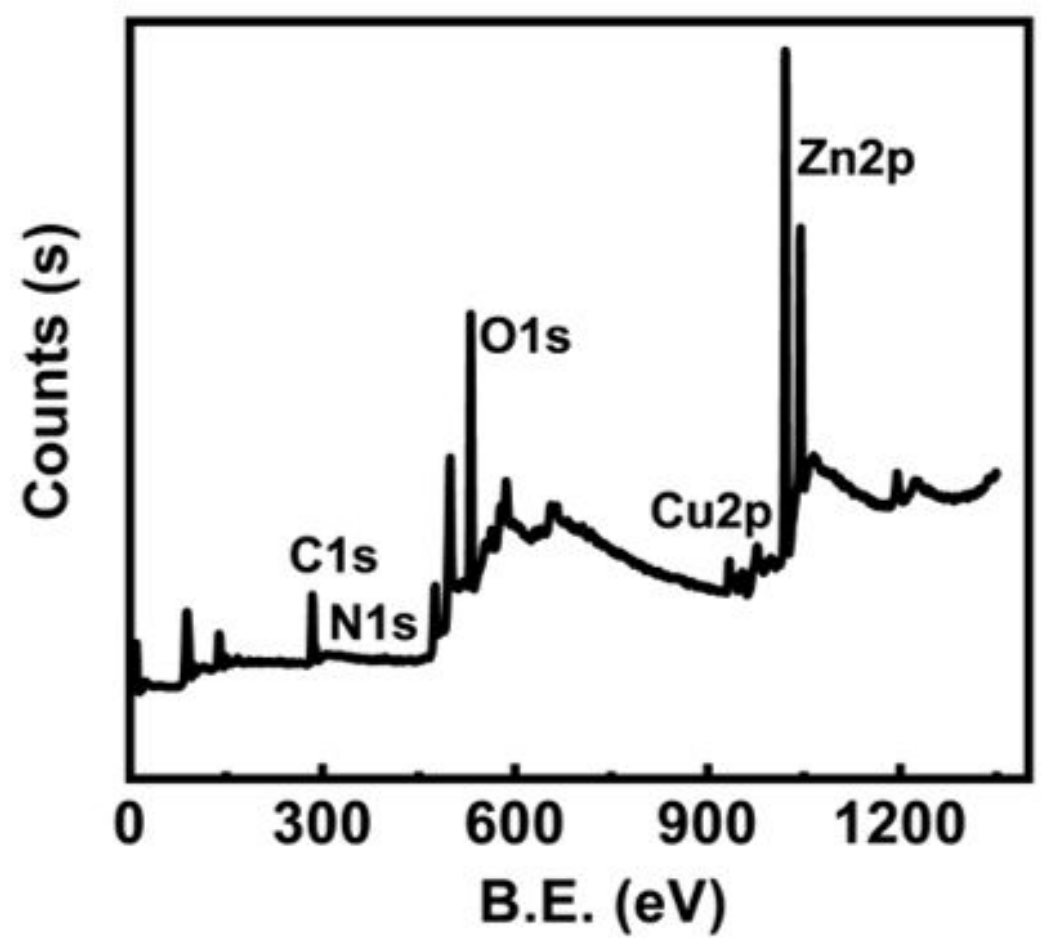

Figure S9. The survey XPS spectra of $\mathrm{ZnTPyP}(\mathrm{Cu})$ film.

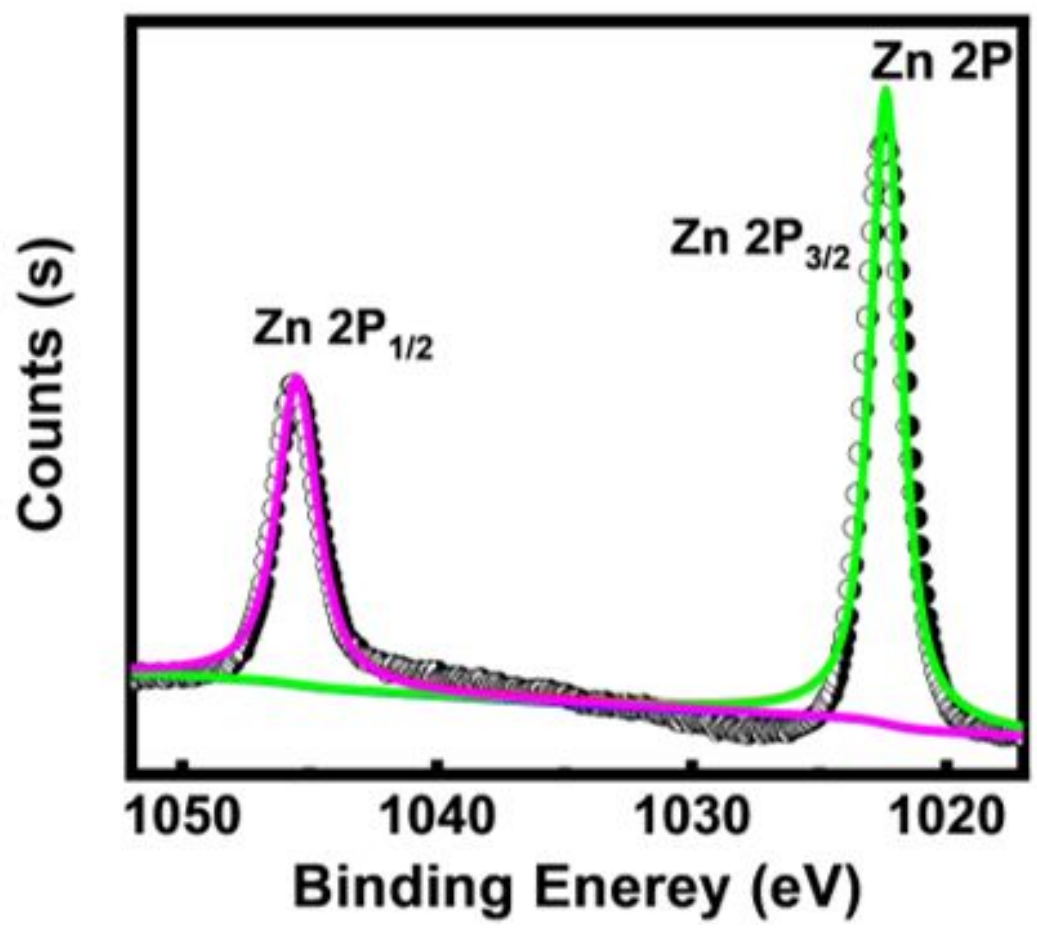

Figure S10. Zn 2p XPS spectra of ZnTPyP(Cu) film. 


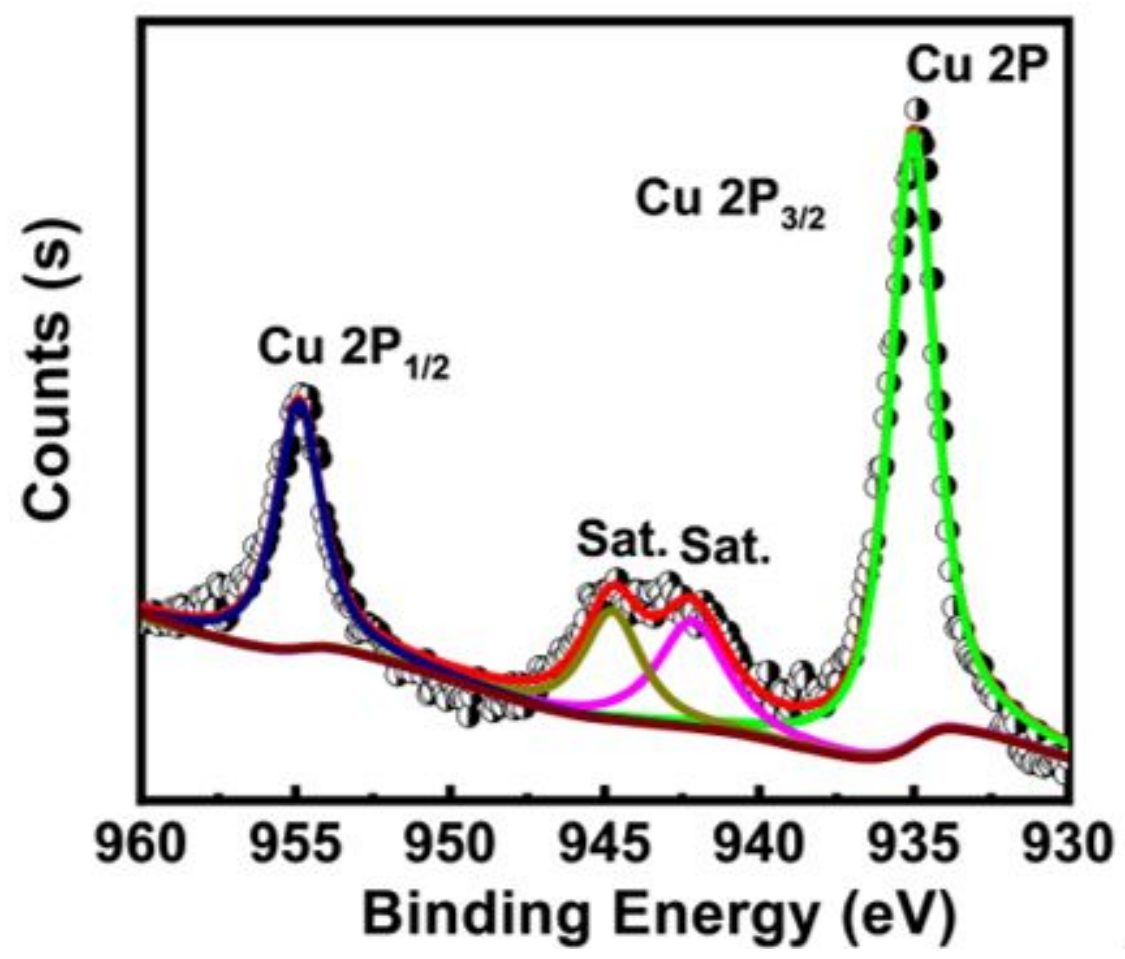

Figure S11. Cu 2p XPS spectra of ZnTPyP(Cu) film.

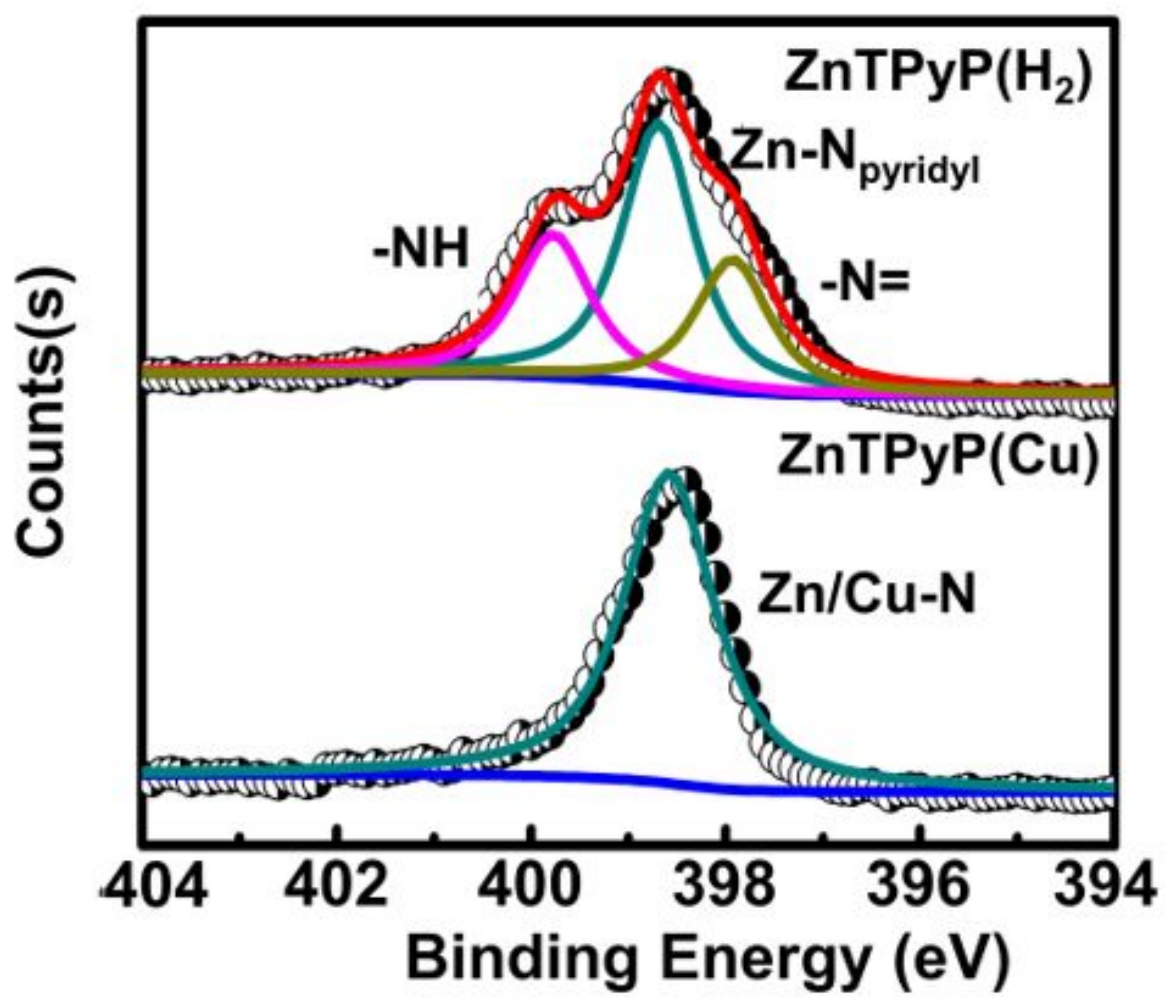

Figure S12. N 1s XPS spectra of $\mathrm{ZnTPyP}(\mathrm{Cu})$ film. 

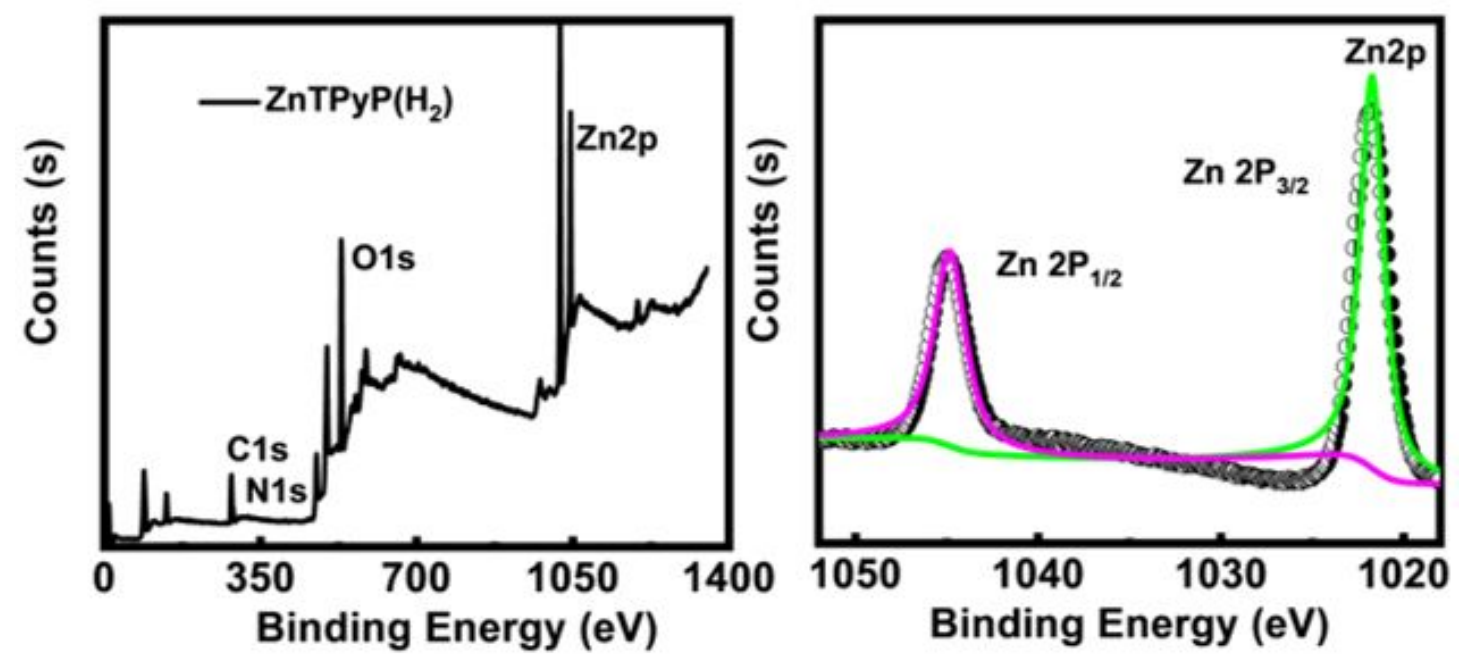

Figure S13. The XPS spectra of $\mathrm{ZnTPyP}\left(\mathrm{H}_{2}\right)$ film.
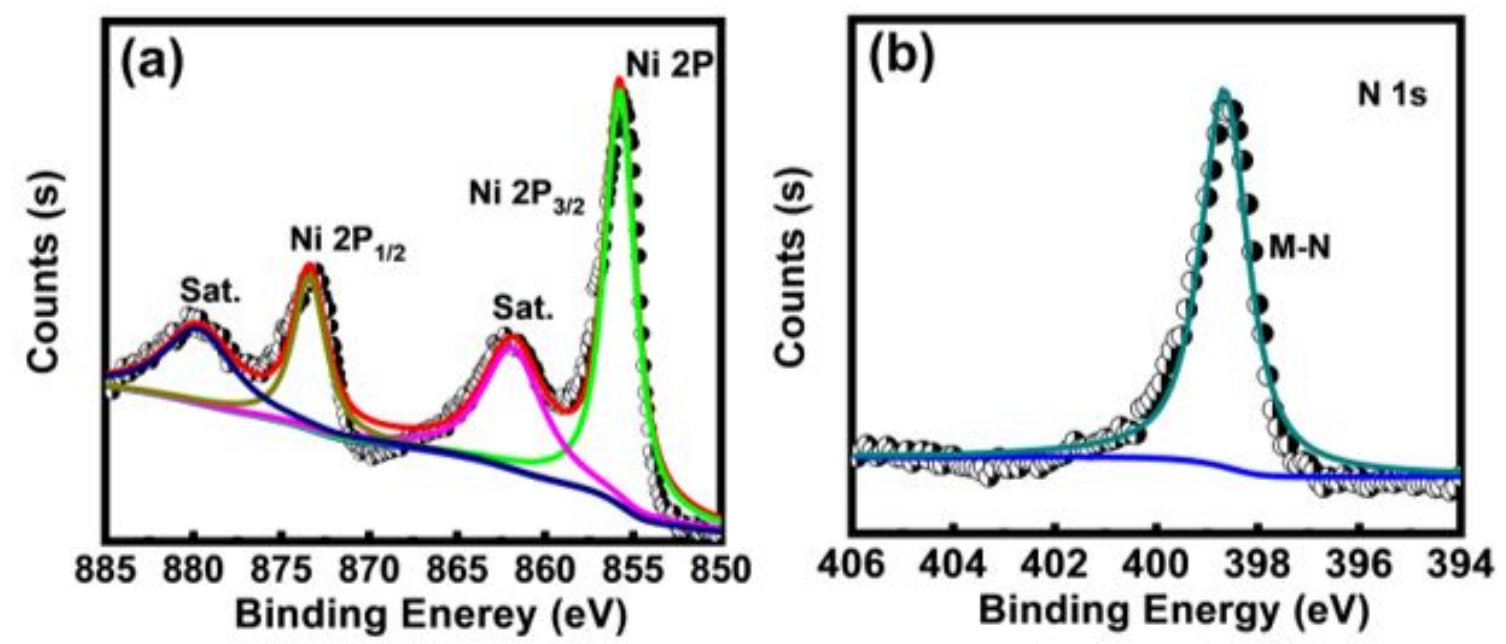

Figure S14. The XPS spectra of ZnTPyP(Ni) film. 

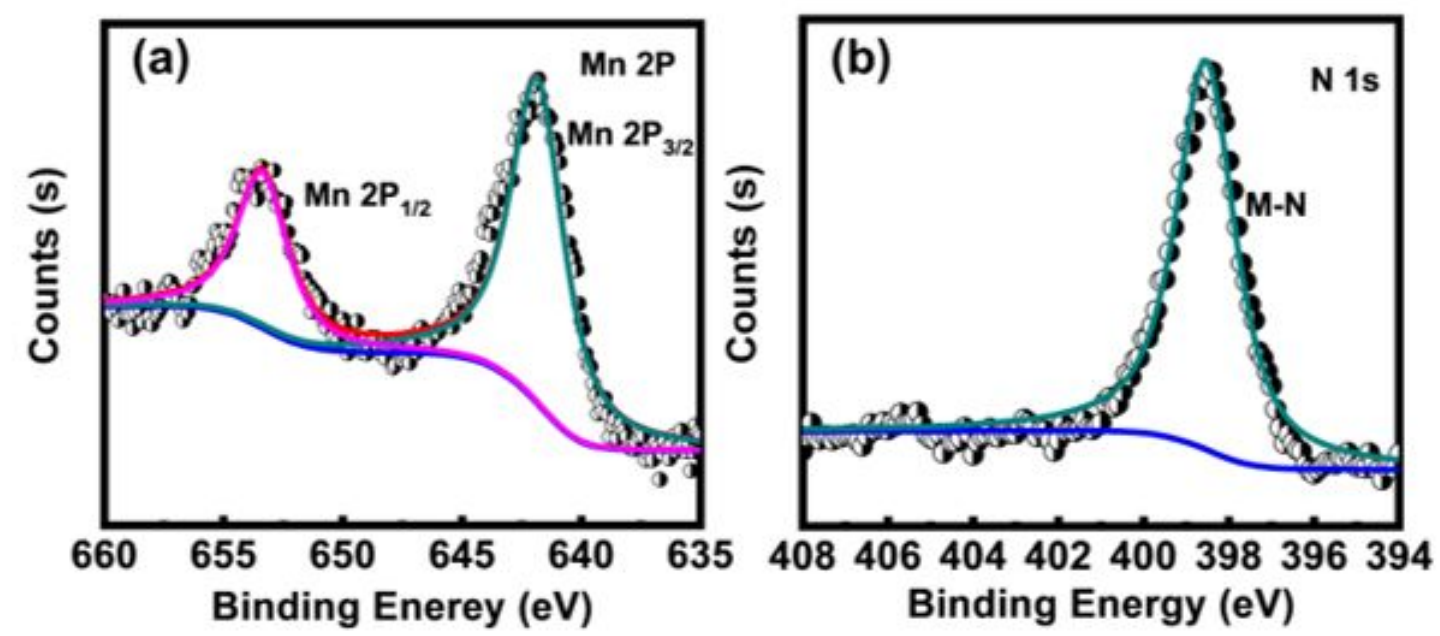

Figure S15. The XPS spectra of ZnTPyP(Mn) film.

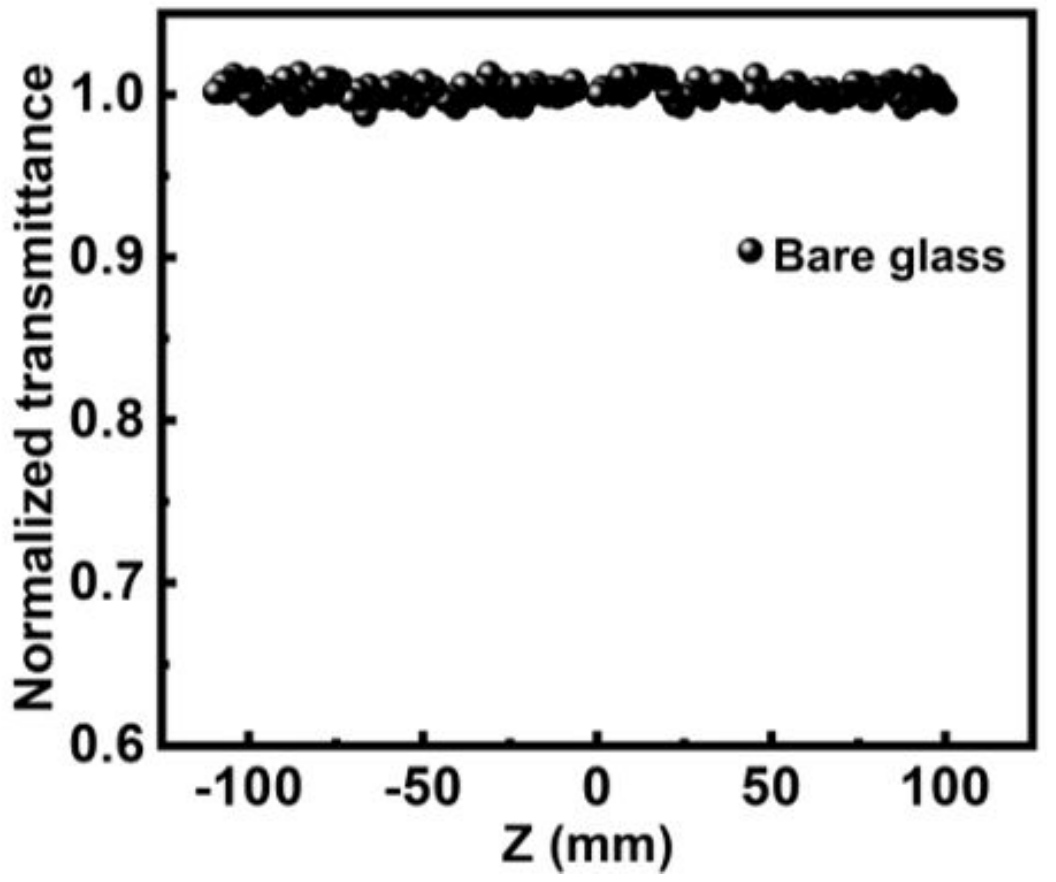

Figure S16. The open-aperture Z-scan plots of bare glass. 


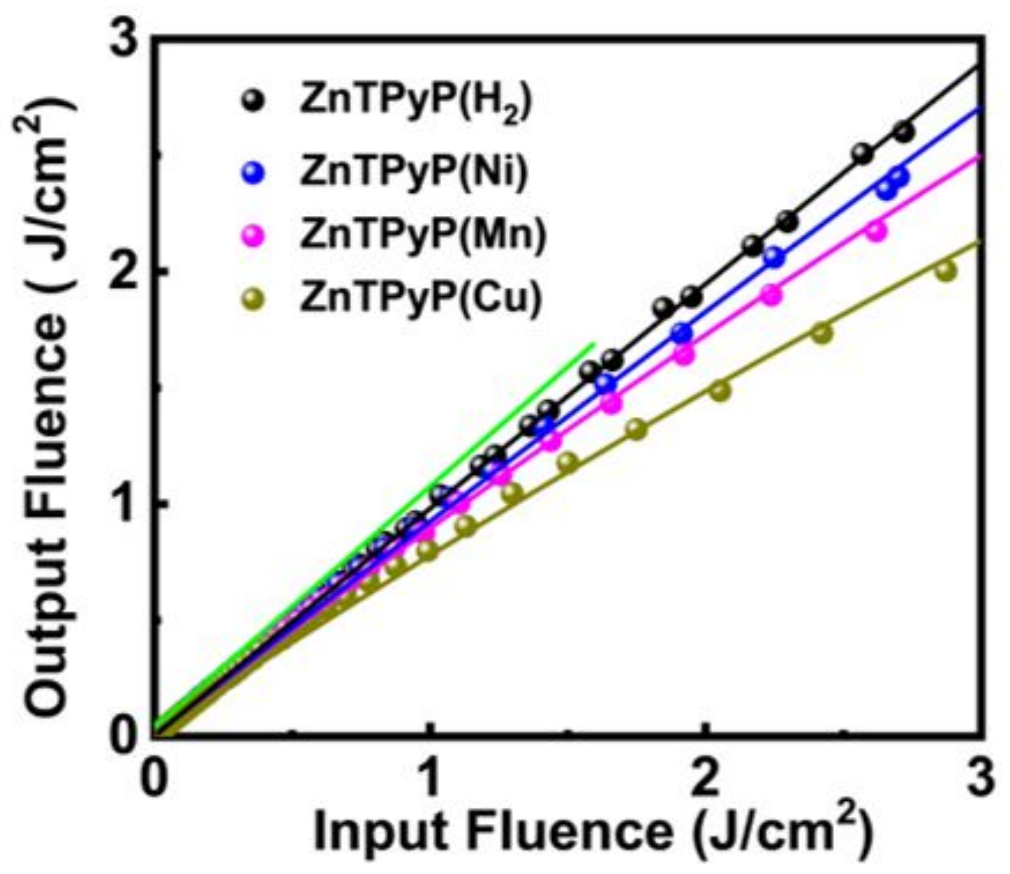

Figure S17. The curves of output fluence versus input fluence for ZnTPyP(M) $(\mathrm{M}=$ $\mathrm{Cu}, \mathrm{Ni}, \mathrm{Mn}, \mathrm{H}_{2}$ ) films.

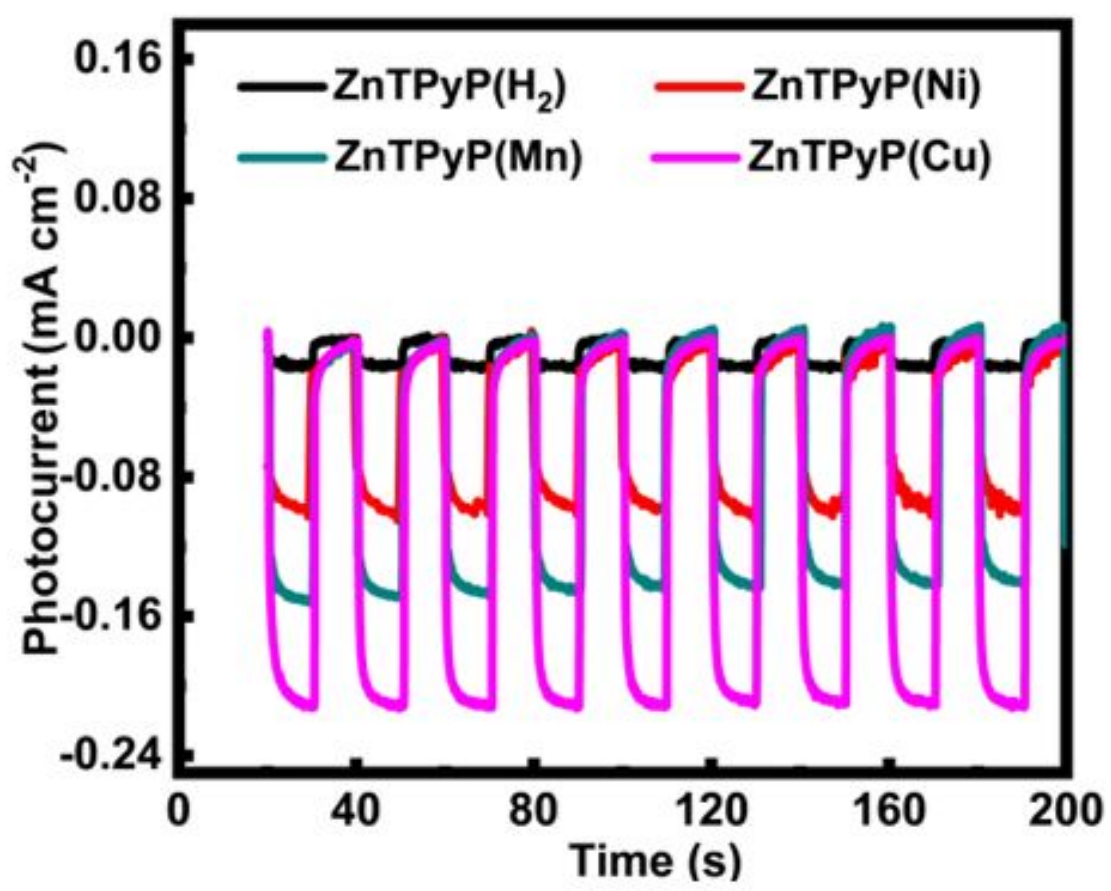

Figure S18. The photocurrent properties for $\mathrm{ZnTPyP}(\mathrm{M})\left(\mathrm{M}=\mathrm{Cu}, \mathrm{Ni}, \mathrm{Mn}, \mathrm{H}_{2}\right)$ films. 


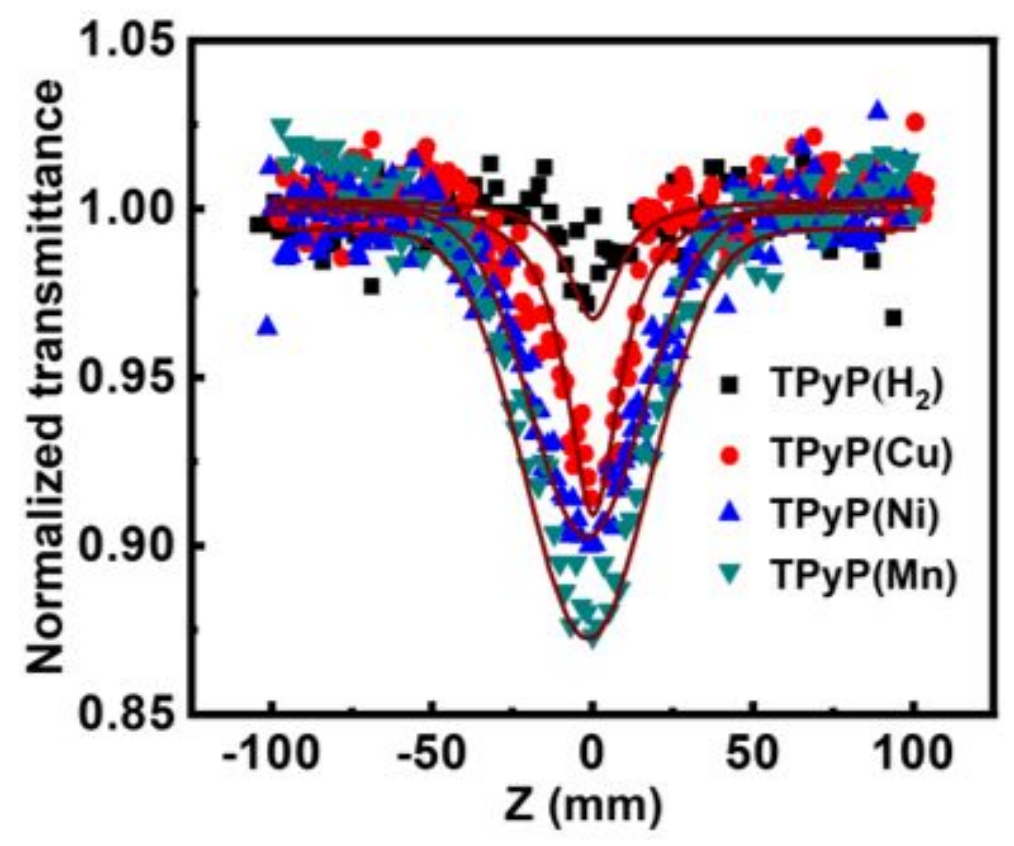

Figure S19. The open-aperture $\mathrm{Z}$-scan curves of TPyP(M) $\left(\mathrm{M}=\mathrm{Cu}, \mathrm{Ni}, \mathrm{Mn}, \mathrm{H}_{2}\right)$ ligand solution.
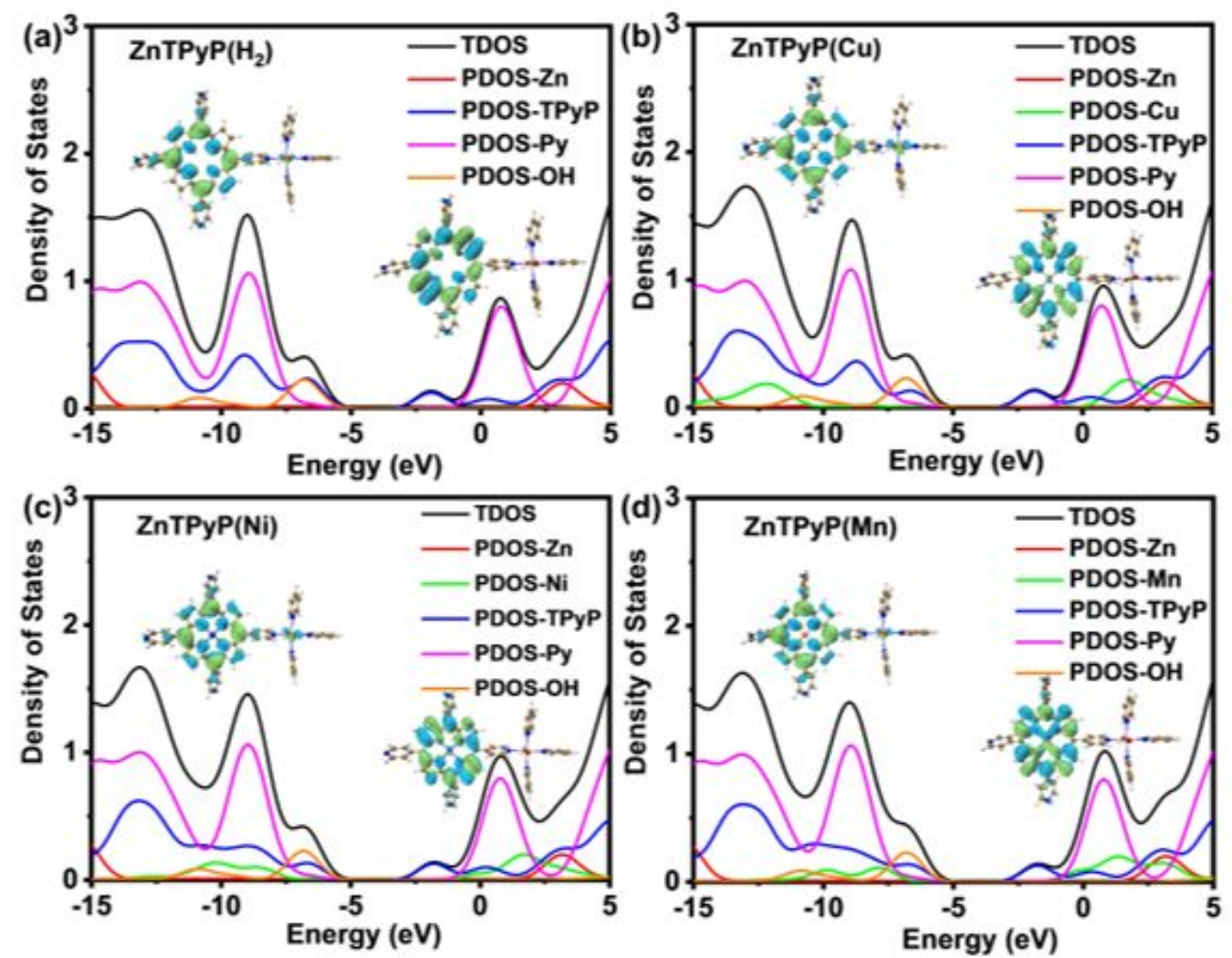

Figure S20. The electronic density of states (DOS) of the $\mathrm{ZnTPyP}(\mathrm{M})(\mathrm{M}=\mathrm{Cu}, \mathrm{Ni}$, $\mathrm{Mn}, \mathrm{H}_{2}$ ) models. 

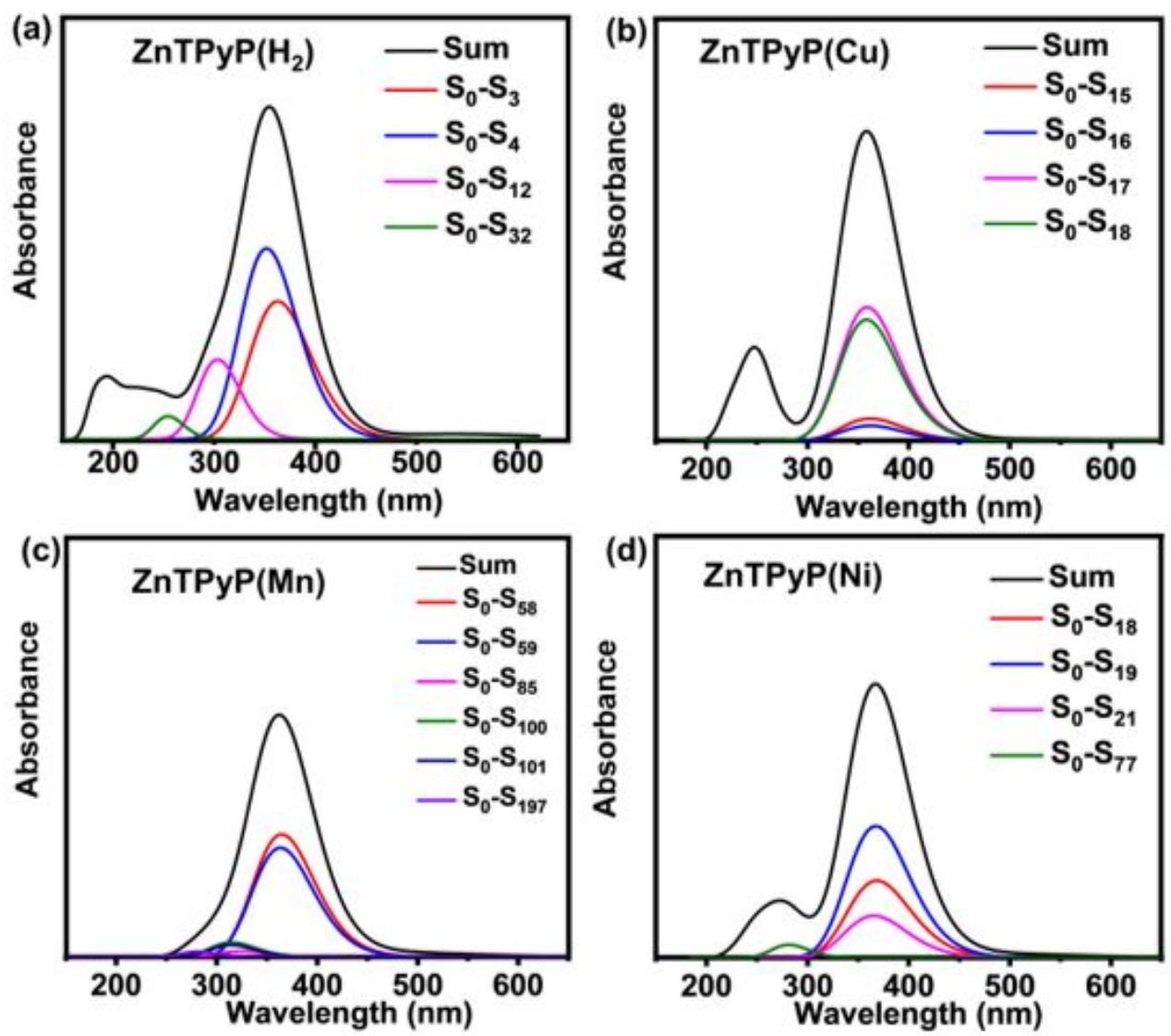

Figure S21. The calculated UV-vis absorption spectra for $\mathrm{ZnTPyP}(\mathrm{M})(\mathrm{M}=\mathrm{Cu}, \mathrm{Ni}$, $\mathrm{Mn}, \mathrm{H}_{2}$ ) models. 

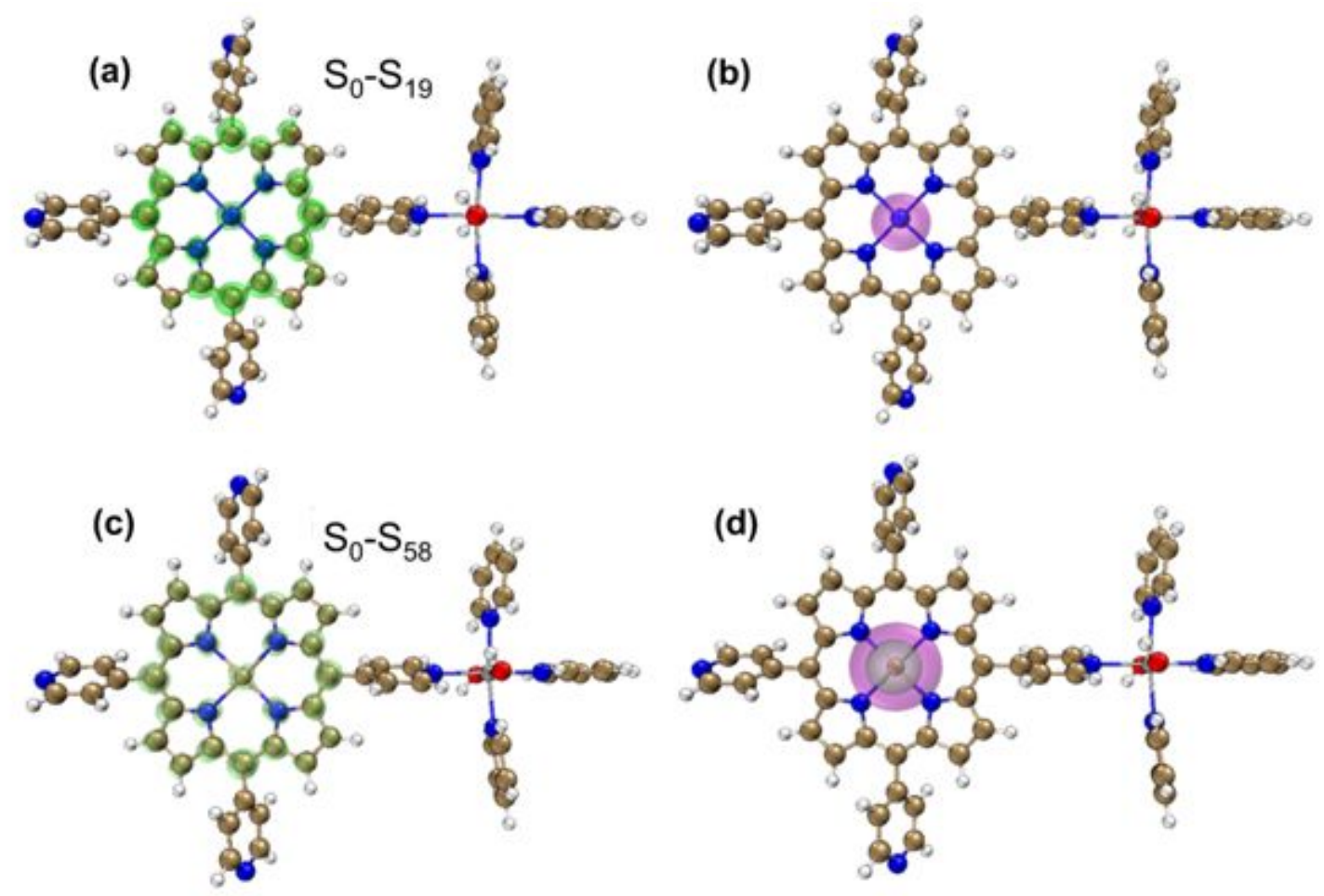

Figure S22. The distribution range and the distribution breadth overlap of the excited holes and electrons in ZnTPyP(Ni) (a, b) and ZnTPyP(Mn) model (c, d). (green: the overlap of holes and elcetrons distribution simultaneously; purple: the isosurface of holes and electrons). 
Table S1. Linear and NLO data of the $\operatorname{ZnTPyP}(M)\left(M=\mathrm{Cu}, \mathrm{Ni}, \mathrm{Mn}, \mathrm{H}_{2}\right)$ films. $\mathrm{T}_{0}$ : linear transmittance; $\beta$ : nonlinear coefficient; $\mathrm{n}_{2}$ : nonlinear refractive coefficients; Im $\chi^{(3)}$ : the imaginary parts of the third-order susceptibility; $\operatorname{Re} \chi^{(3)}$ : the real parts of the third-order susceptibility; $\chi^{(3)}$ :the absolute value of the third-order susceptibility.

\begin{tabular}{|c|c|c|c|c|c|c|}
\hline Samples & $\mathrm{T}_{\min }$ & $\begin{array}{c}\beta \\
\left(\times 10^{-7}\right. \\
\mathrm{m} / \mathrm{W})\end{array}$ & $\begin{array}{c}\mathrm{n}_{2} \\
\left(\times 10^{-14}\right. \\
\left.\mathrm{m}^{2} / \mathrm{W}\right)\end{array}$ & $\begin{array}{c}\operatorname{Im} \chi^{(3)} \\
\left(\times 10^{-8}\right. \\
\text { esu })\end{array}$ & $\begin{array}{c}\operatorname{Re} \chi^{(3)} \\
\left(\times 10^{-8}\right. \\
\text { esu })\end{array}$ & $\begin{array}{c}\chi^{(3)} \\
\left(\times 10^{-8}\right. \\
e s u)\end{array}$ \\
\hline $\mathrm{ZnTPyP}(\mathrm{Cu})$ & $\sim 0.61$ & $\sim 57$ & $\sim-92$ & $\sim 13.8$ & $\sim-52.5$ & $\sim 54.3$ \\
\hline ZnTPyP(Ni) & $\sim 0.81$ & $\sim 18$ & $\sim-71$ & $\sim 4.36$ & $\sim-40.5$ & $\sim 40.7$ \\
\hline ZnTPyP(Mn) & $\sim 0.86$ & $\sim 12$ & $\sim-66$ & $\sim 2.91$ & $\sim-37.6$ & $\sim 37.7$ \\
\hline $\mathrm{ZnTPyP}\left(\mathrm{H}_{2}\right)$ & $\sim 0.94$ & $\sim 5.1$ & $\sim-6.5$ & $\sim 1.23$ & $\sim-3.71$ & $\sim 3.91$ \\
\hline
\end{tabular}


Table S2. NLO data for this work and some literature examples.

\begin{tabular}{|c|c|c|c|}
\hline Samples & $\beta(\mathbf{m} / \mathbf{W})$ & $\chi^{(3)}(e s u)$ & Refs. \\
\hline $\mathrm{ZnTPyP}(\mathrm{Cu})$ film & $\sim 5.7 \times 10^{-6}$ & $\sim 5.43 \times 10^{-7}$ & In this work \\
\hline ZnTPyP(Ni) film & $\sim 1.8 \times 10^{-6}$ & $\sim 4.07 \times 10^{-7}$ & In this work \\
\hline ZnTPyP(Mn) film & $\sim 1.2 \times 10^{-6}$ & $\sim 3.77 \times 10^{-7}$ & In this work \\
\hline $\mathrm{ZnTPyP}\left(\mathrm{H}_{2}\right)$ film & $\sim 5.1 \times 10^{-7}$ & $\sim 3.91 \times 10^{-8}$ & In this work \\
\hline$\left(\mathrm{Zn}_{2} \mathrm{Al}-\mathrm{LDH} / \mathrm{ZnTPPS}\right)_{40}$ & -- & $7.86 \times 10^{-11}$ & 9 \\
\hline PIZA-1 thin film & $1.9 \times 10^{-6}$ & $7.7 \times 10^{-8}$ & \multirow{2}{*}{10} \\
\hline $\mathrm{C}_{60} @$ PIZA-1 thin film & $2.8 \times 10^{-6}$ & $1.1 \times 10^{-7}$ & \\
\hline $\begin{array}{c}{\left[\mathrm{H}_{2} \mathrm{TPP}\right]-} \\
{\left[\mathrm{H}_{2} \mathrm{ZnMo}_{6} \mathrm{O}_{18}\left\{\left(\mathrm{OCH}_{2}\right)_{3} \mathrm{CNH}_{2}\right\}_{2}\right] \cdot 2(} \\
\left.\mathrm{C}_{2} \mathrm{H}_{5}\right)_{2} \mathrm{O}\end{array}$ & $3.17 \times 10^{-5} \mathrm{esu}$ & $2.7 \times 10^{-10}$ & 11 \\
\hline$\left(\mathrm{NH}_{2}\right)_{4} \mathrm{TPPMn} @ \mathrm{HPA}$ & $1.67 \times 10^{-5} \mathrm{esu}$ & $3.35 \times 10^{-11}$ & 12 \\
\hline PAE-azo-CoPc & $2 \times 10^{-10} e s u$ & $5.18 \times 10^{-11}$ & 13 \\
\hline Zn-THPP & $4.6 \times 10^{-10}$ & $1.52 \times 10^{-11}$ & 14 \\
\hline Co-THPP (ultrathin films) & $9.5 \times 10^{-10}$ & $3.13 \times 10^{-11}$ & 15 \\
\hline Copper porphyrin & $1.32 \times 10^{-9}$ & -- & \multirow{3}{*}{16} \\
\hline Zinc porphyrin & $3.66 \times 10^{-9}$ & -- & \\
\hline Pure grapheme & $9.0 \times 10^{-9}$ & -- & \\
\hline Por-TzTz-POF & $1.1 \times 10^{-8}$ & -- & 17 \\
\hline Por-COF-HH & $1.04 \times 10^{-8}$ & -- & \multirow{3}{*}{18} \\
\hline Por-COF-ZnNi & $4.17 \times 10^{-8}$ & -- & \\
\hline Por-COF- $\mathrm{ZnCu}$ & $4.47 \times 10^{-8}$ & -- & \\
\hline $\mathrm{MoS}_{2} / \mathrm{PMMA}$ & $9.7 \times 10^{-9}$ & -- & 19 \\
\hline $\mathrm{MoS}_{2}-\mathrm{pvk}$ & $9.17 \times 10^{-9}$ & -- & 20 \\
\hline PFTP-RGO/PMMA & $2.96 \times 10^{-9}$ & $1.26 \times 10^{-10}$ & 21 \\
\hline
\end{tabular}




\begin{tabular}{|c|c|c|c|}
\hline BP:C 60 & $2.41 \times 10^{-9}$ & -- & 22 \\
\hline PF-RGO & $7.07 \times 10^{-11}$ & -- & 23 \\
\hline 3D tetrazine chromophore MOFs & $(2.8-4.6) \times 10^{-12}$ & -- & 24 \\
\hline Pt-Ni cluster/rGO & $1.98 \times 10^{-11}$ & -- & 25 \\
\hline$\left[\mathrm{WS}_{4} \mathrm{Cu}_{3}\left(4,4^{\prime}-\mathrm{pytz}\right)_{3}\right] \cdot\left[\mathrm{N}(\mathrm{CN})_{2}\right]$ & $4.6 \times 10^{-10}$ & -- & 26 \\
\hline
\end{tabular}

Table S3. The second hyperpolarizabilities $(\gamma)$ of $\mathrm{ZnTPyP}(\mathrm{M})\left(\mathrm{M}=\mathrm{Cu}, \mathrm{Ni}, \mathrm{Mn}, \mathrm{H}_{2}\right)$ models calculated by the CPHF method.

\begin{tabular}{|c|c|c|c|c|c|c|}
\hline Samples & $\gamma$ & $\gamma_{\mathrm{xxxx}}$ & $\gamma_{\mathrm{yyyy}}$ & $\gamma_{\mathrm{zzzz}}$ & $\gamma$ & $\gamma_{\perp}$ \\
\hline ZnTPyP(Cu) & $5.10 \mathrm{E}+0$ & $2.34 \mathrm{E}+0$ & $7.71 \mathrm{E}+0$ & $1.34 \mathrm{E}+0$ & $6.58 \mathrm{E}+0$ & $2.19 \mathrm{E}+0$ \\
& 5 & 6 & 5 & 4 & 5 & 5 \\
\hline ZnTPyP(Ni) & $4.98 \mathrm{E}+0$ & $2.23 \mathrm{E}+0$ & $7.41 \mathrm{E}+0$ & $2.07 \mathrm{E}+0$ & $6.60 \mathrm{E}+0$ & $2.20 \mathrm{E}+0$ \\
& 5 & 6 & 5 & 4 & 5 & 5 \\
\hline ZnTPyP(Mn & $4.63 \mathrm{E}+0$ & $2.10 \mathrm{E}+0$ & $7.23 \mathrm{E}+0$ & $1.41 \mathrm{E}+0$ & $6.03 \mathrm{E}+0$ & $2.01 \mathrm{E}+0$ \\
& 5 & 6 & 5 & 4 & 5 & 5 \\
\hline ZnTPyP $\left(\mathrm{H}_{2}\right)$ & $2.42 \mathrm{E}+0$ & $1.07 \mathrm{E}+0$ & $6.56 \mathrm{E}+0$ & $9.09 \mathrm{E}+0$ & $3.38 \mathrm{E}+0$ & $1.13 \mathrm{E}+0$ \\
& 5 & 6 & 5 & 3 & 5 & 5 \\
\hline
\end{tabular}

Table S4. Crucial vertical excitation properties of $\mathrm{ZnTPyP}(\mathrm{M})\left(\mathrm{M}=\mathrm{Cu}, \mathrm{Ni}, \mathrm{Mn}, \mathrm{H}_{2}\right)$ models. $\lambda_{\max }$ : the maximum absorption wavelength; $\mathrm{f}$ : the oscillation strength; $\mathrm{H}$ and $\mathrm{L}$ denote HOMO and LUMO, respectively.

\begin{tabular}{|c|c|c|l|}
\hline Samples & $\lambda_{\max }(\mathrm{nm})$ & $\mathrm{f}$ & \multicolumn{1}{c|}{ Electronic transition } \\
\hline ZnTPyP $(\mathrm{Cu})$ & 359 & 1.179 & $\begin{array}{l}\mathrm{S}_{17}: \mathrm{Hb}-2->\mathrm{Lb} 22.0 \%, \mathrm{Ha}->\mathrm{La}+119.9 \%, \\
\mathrm{Ha}-2->\mathrm{La} 16.9 \%, \mathrm{Hb}->\mathrm{Lb}+116.2 \%\end{array}$ \\
\hline ZnTPyP(Ni) & 368 & 1.1564 & $\mathrm{~S}_{19}: \mathrm{H}-5->\mathrm{L} 46.1 \%, \mathrm{H}-4$-> L $+136.3 \%$ \\
\hline
\end{tabular}




\begin{tabular}{|l|c|l|l|}
\hline ZnTPyP(Mn) & 364 & 1.2458 & $\begin{array}{l}\mathrm{S}_{58}: \mathrm{Hb}-7 \text {-> Lb 28.2\%, Ha-5 -> La 24.2\%, } \\
\mathrm{Ha}-4 \text {-> La+1 19.9\%, Hb-6 -> Lb+1 19.1\% }\end{array}$ \\
\hline ZnTPyP $\left(\mathrm{H}_{2}\right)$ & 352 & 1.6775 & $\mathrm{~S}_{4}: \mathrm{H}-3$-> L 41.4\%, H -> L+1 36.9\% \\
\hline
\end{tabular}

Table S5. The strongest excited characteristics of $\mathrm{ZnTPyP}(\mathrm{M})\left(\mathrm{M}=\mathrm{Cu}, \mathrm{Ni}, \mathrm{Mn}, \mathrm{H}_{2}\right)$ models. (ZnTPyP $(\mathrm{Cu}): \quad \mathrm{S}_{0}-\mathrm{S}_{17} ; \quad \mathrm{ZnTPyP}\left(\mathrm{H}_{2}\right): \mathrm{S}_{0}-\mathrm{S}_{4} ; \quad \mathrm{ZnTPyP}(\mathrm{Mn}): \mathrm{S}_{0}-\mathrm{S}_{58}$ and ZnTPyP(Ni): $\mathrm{S}_{0}-\mathrm{S}_{19}$; LE: local excitation; MLCT: metal-ligand charge transfer; LLCT: ligand-ligand charge transfer).

\begin{tabular}{|c|c|c|c|}
\hline Samples & MLCT (\%) & LLCT (\%) & LE (\%) \\
\hline ZnTPyP(Cu) & 0.78 & 2.45 & 95.29 \\
\hline ZnTPyP(Ni) & 0.77 & 4.88 & 92.65 \\
\hline ZnTPyP(Mn) & 1.08 & 7.69 & 92.41 \\
\hline ZnTPyP $\left(\mathrm{H}_{2}\right)$ & -- & 3.35 & 91.34 \\
\hline
\end{tabular}

Table S6. The corresponding parameters of holes and electrons. D: the centroid distance; Sr: the overlap of holes and elcetrons; H: the width distrubution of holes and elcetrons; $t$ : the degree of separation for holes and electrons; Ecoul: holes-electrons coulomb attractive energy; HDI: holes delocalization exponent; EDI: electrons localization index; $\Delta \sigma$ : the difference in the overall spatial distribution of electrons and holes.

\begin{tabular}{|c|c|c|c|c|c|c|c|c|}
\hline Samples & $\begin{array}{c}\mathrm{D} \\
(\AA)\end{array}$ & $\begin{array}{c}\mathrm{Sr} \\
(\text { a.u. })\end{array}$ & $\begin{array}{c}\mathrm{H} \\
(\AA)\end{array}$ & $\begin{array}{c}\mathrm{t} \\
(\AA)\end{array}$ & $\begin{array}{c}\text { Ecoul } \\
(\mathrm{eV})\end{array}$ & HDI & $\begin{array}{c}\text { EDI } \\
(\AA)\end{array}$ \\
\hline ZnTPyP(Cu) & 0.076 & 0.970 & 3.766 & -2.579 & 4.15 & 4.56 & 4.63 & 0.263 \\
\hline ZnTPyP(Ni) & 0.203 & 0.955 & 3.762 & -2.365 & 4.09 & 4.66 & 5.29 & 0.263 \\
\hline
\end{tabular}




\begin{tabular}{|l|l|l|l|l|l|l|l|l|}
\hline ZnTPyP(Mn) & 0.049 & 0.955 & 3.904 & -2.633 & 4.03 & 4.35 & 4.43 & 0.299 \\
\hline ZnTPyP $\left(\mathrm{H}_{2}\right)$ & 0.112 & 0.962 & 3.884 & -2.641 & 4.00 & 4.61 & 4.62 & 0.176 \\
\hline
\end{tabular}

\section{References}

(1) Aya, T.; Hamilton, A. D., Tetrabiphenylporphyrin-Based Receptors for Protein Surfaces Show Sub-Nanomolar Affinity and Enhance Unfolding. Bioorg. Med. Chem. Lett. 2003, 13 (16), 2651-2654.

(2) Lin, Q.; Mao, C.; Kong, A.; Bu, X.; Zhao, X.; Feng, P., Porphyrinic Coordination Lattices with Fluoropillars. J. Mater.Chem. A 2017, 5 (40), 21189-21195.

(3) Wen, L.; Fang, Y.; Yang, J.; Han, Y.; Song, Y., Comparison of Third-Order Nonlinear Optical Properties of Benzothiazolium Salt and Neutral Benzothiazole Derivative: Broadband Absorption Response and Transient Dynamic Analysis. Dyes and Pigments 2019, 168, 28-35.

(4) Perumbilavil, S.; Lopez-Ortega, A.; Tiwari, G. K.; Nogues, J.; Endo, T.; Philip, R., Enhanced Ultrafast Nonlinear Optical Response in Ferrite Core/Shell Nanostructures with Excellent Optical Limiting Performance. Small 2018, 14 (6), 1701001.

(5) Gaussian 16, M. J. Frisch, G. W. Trucks, H. B. Schlegel, G. E. Scuseria, et. al., Gaussian, Inc., Wallingford CT, 2016.

(6) Gong, Y. N.; Zhong, W.; Li, Y.; Qiu, Y.; Zheng, L.; Jiang, J.; Jiang, H. L., Regulating Photocatalysis by Spin-State Manipulation of Cobalt in Covalent Organic Frameworks. J. Am. Chem. Soc. 2020, 142 (39), 16723-16731. 
(7) Lu, T.; Chen, F., Multiwfn: A Multifunctional Wavefunction Analyzer. J. Comput. Chem. 2012, 33 (5), 580-592.

(8) Meyers, F.; Marder, S. R.; Pierce, B. M.; Bredas, J. L., Electric Field Modulated Nonlinear Optical Properties of Donor-Acceptor Polyenes: Sum-Over-States Investigation of the Relationship between Molecular Polarizabilities ( $\alpha, \beta$, and $\gamma)$ and Bond Length Alternation. J. Am. Chem. Soc. 1994, 116 (23), 10703-10714.

(9) Ren, X.; Ren, H.; Zhou, Y.; Zhang, L.; Shehzad, F. K.; Li, C., (Zn2AlLDH/ZnTPPS)n Composite Films with Notable Third-Order Optical Nonlinearities. $J$. Porphyr. Phthalocyanines 2018, 22 (09n10), 758-763.

(10) Li, D.-J.; Gu, Z.-G.; Zhang, J., Auto-Controlled Fabrication of a Metal-Porphyrin Framework Thin Film with Tunable Optical Limiting Effects. Chem. Sci. 2020, 11 (7), $1935-1942$.

(11) Shehzad, F. K.; Zhou, Y.; Zhang, L.; Long, Y.; Maitlo, I.; Iqbal, A.; Yang, D., Anionic Effect of $\delta$ and $\chi$ Forms of Tris(alkoxo) Ligand Functionalized Anderson-Type Polyoxometalates on Nonlinear Optical Response of Porphyrin-POM Based Supramolecular Compounds. J. Phy. Chem. C 2018, 122 (2), 1280-1287.

(12) Hassan, S. u.; Nawaz, F.; Haq Khan, Z. U.; Firdous, A.; Farid, M. A.; Nazir, M. S., Optical materials: Studying the Role of Hetropolyacid to Enhance the Nonlinear Optical Responses of Porphyrin in Their Hybrids System. Opt. Mater. 2018, 86, 106112.

(13) Zhang, Y.; Gai, S.; Wang, Z.; Wang, S.; Sui, A.; Song, X.-M., Poly(Arylene Ether)s with Aromatic Azo-Coupled Cobalt Phthalocyanines in the Side Chain: 
Synthesis, Characterization and Nonlinear Optical and Optical Limiting Properties. RSC Adv. 2019, 9 (16), 9253-9259.

(14) Xu, B.-W.; Niu, R.-J.; Liu, Q.; Yang, J.-Y.; Zhang, W.-H.; Young, D. J., Similarities and Differences between $\mathrm{Mn}$ (II) and $\mathrm{Zn}$ (II) Coordination Polymers Supported by Porphyrin-Based Ligands: Synthesis, Structures and Nonlinear Optical Properties. Dalton Trans. 2020, 49 (36), 12622-12631.

(15) Niu, R.-J.; Zhou, W.-F.; Liu, Y.; Yang, J.-Y.; Zhang, W.-H.; Lang, J.-P.; Young, D. J., Morphology-Dependent Third-Order Optical Nonlinearity of a 2D Co-Based Metal-Organic Framework with a Porphyrinic Skeleton. Chem. Commun. 2019, 55 (33), 4873-4876.

(16) Krishna, M. B. M.; Kumar, V. P.; Venkatramaiah, N.; Venkatesan, R.; Rao, D. N., Nonlinear Optical Properties of Covalently Linked Graphene-Metal Porphyrin Composite Materials. Appl. Phy. Lett. 2011, 98 (8), 081106.

(17) Samal, M.; Valligatla, S.; Saad, N. A.; Rao, M. V.; Rao, D. N.; Sahu, R.; Biswal, B. P., A Thiazolo 5,4-d Thiazole-Bridged Porphyrin Organic Framework as a Promising Nonlinear Optical Material. Chem. Commun. 2019, 55 (74), 11025-11028.

(18) Biswal, B. P.; Valligatla, S.; Wang, M.; Banerjee, T.; Saad, N. A.; Mariserla, B. M. K.; Chandrasekhar, N.; Becker, D.; Addicoat, M.; Senkovska, I.; Berger, R.; Rao, D. N.; Kaskel, S.; Feng, X., Nonlinear Optical Switching in Regioregular Porphyrin Covalent Organic Frameworks. Angew. Chem. Int. Ed. 2019, 58 (21), 6896-6900. 
(19) Liang, G. W.; Tao, L. L.; Tsang, Y. H.; Zeng, L. H.; Liu, X.; Li, J.; Qu, J. L.; Wen, Q., Optical Limiting Properties of A Few-Layer $\mathrm{MoS}_{2} / \mathrm{PMMA}$ Composite under Excitation of Ultrafast Laser Pulses. J. Mater. Chem. C 2019, 7 (3), 495-502.

(20) Cheng, H.; Dong, N.; Bai, T.; Song, Y.; Wang, J.; Qin, Y.; Zhang, B.; Chen, Y., Covalent Modification of $\mathrm{MoS}_{2}$ with Poly(N-vinylcarbazole) for Solid-State Broadband Optical Limiters. Chem. Eur. J. 2016, 22 (13), 4500-4507.

(21) Liu, Z.; Dong, N.; Jiang, P.; Wang, K.; Wang, J.; Chen, Y., Reduced Graphene Oxide Chemically Modified with Aggregation-Induced Emission Polymer for SolidState Optical Limiter. Chem. Eur. J. 2018, 24 (72), 19317-19322.

(22) Shi, M.; Huang, S.; Dong, N.; Liu, Z.; Gan, F.; Wang, J.; Chen, Y., Donor-acceptor type blends composed of black phosphorus and $\mathrm{C}_{60}$ for solid-state optical limiters. Chem. Commun. 2018, 54 (4), 366-369.

(23) Du, Y.; Dong, N.; Zhang, M.; Zhu, K.; Na, R.; Zhang, S.; Sun, N.; Wang, G.; Wang, J., Covalent Functionalization of Graphene Oxide with Porphyrin and Porphyrin Incorporated Polymers for Optical Limiting. Phy. Chem. Chem. Phy. 2017, 19 (3), $2252-2260$.

(24) Li, J.; Jia, D.; Meng, S.; Zhang, J.; Cifuentes, M. P.; Humphrey, M. G.; Zhang, C., Tetrazine Chromophore-Based Metal-Organic Frameworks with Unusual Configurations: Synthetic, Structural, Theoretical, Fluorescent, and Nonlinear Optical Studies. Chem. Eur. J. 2015, 21 (21), 7914-7926.

(25) Zheng, C.; Lei, L.; Huang, J.; Chen, W.; Li, W.; Wang, H.; Huang, L.; Huang, D., Facile Control of Metal Nanoparticles from Isolated Nanoparticles to Aggregated 
Clusters on Two-Dimensional Graphene to Form Optical Limiters. J. Mater. Chem. C 2017, 5 (44), 11579-11589.

(26) Li, J.; Jia, D.; Meng, S.; Zhang, J.; Cifuentes, M. P.; Humphrey, M. G.; Zhang, C., Tetrazine Chromophore-based Metal-Organic Frameworks with Unusual Configurations: Synthetic, Structural, Theoretical, Fluorescent, and Nonlinear optical studies. Chem.Eur.J. 2015, 21 (21), 7914-26. 